$[r \cdot q-r q)] ص$

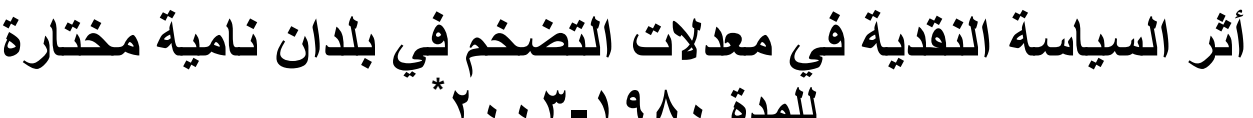

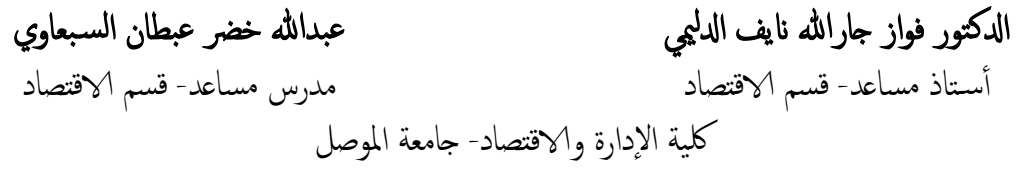

\section{المستخلص المص}

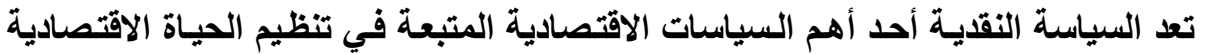

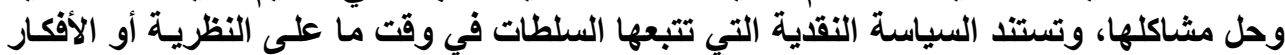

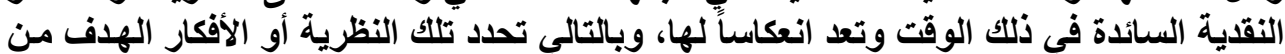

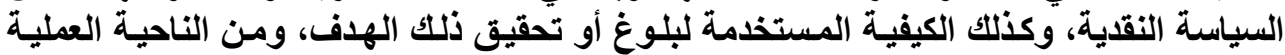

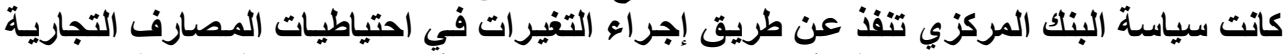

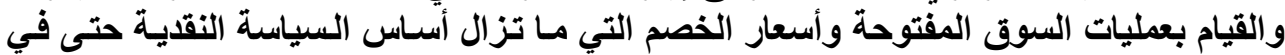

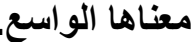

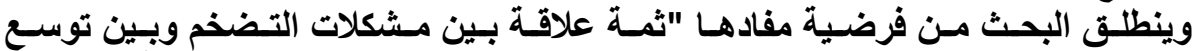

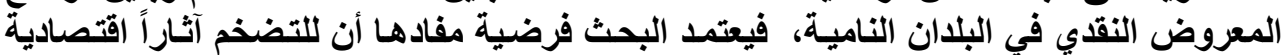

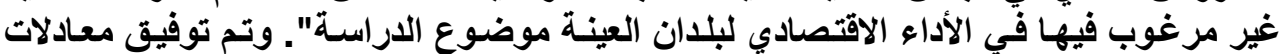

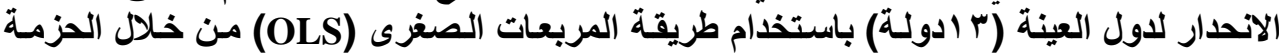

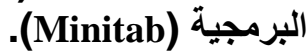

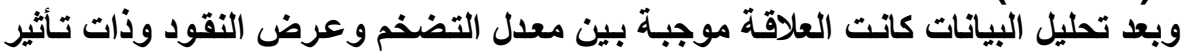

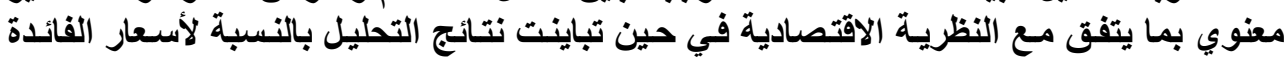
وسعر الصرف.

$$
\begin{aligned}
& \text { * البحث مستل من رسالة ماجستير الموسومة " أثر السياسة النقدية في معدلات التضخم في بلدان }
\end{aligned}
$$

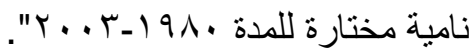

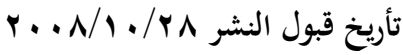

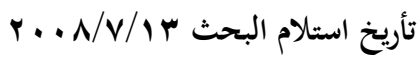


الدكتور الدليمي والسبعاوي [rar]

\title{
The impact of Monetary Policy in Inflation Rates in Selected Developing Countries for the Period from 1980 to 2003
}

\author{
Fawaz J. Al-Dlaimi (phD) \\ Assistant Professor \\ Department of Economics \\ University of Mosul \\ fawazaldellemi@yahoo.com
}

\author{
Abdullah K. Al-Sabaawe \\ Assistant Lecturer \\ Department of Economics \\ University of Mosul \\ aalsabaawe@yahoo.com
}

\begin{abstract}
The monetary policy is considered to be one of the most important economic policies used in organizing economic life and solving its problems. The monetary policy followed by authorities at one time is based on a theory or monetary ideas prevailed at that time which in turn formulates the aim of the monetary policy and the method to achieve that aim. Practically speaking, the policy of the Central Bank was implemented by changing the reserves of the commercial banks and practicing the operations of the open market and discount prices which still constitute the basis of the monetary policy even in its wide concept. The research stems from the premise that "there is a relationship between the problems of inflation and the expansion of the monetary supply in developing countries. The research premises that economic effects of inflation unwanted in the economic performance of countries in the sample in question." The regression equations for the sample (13 States) have been done using the method of least squares (OLS) through a software package (Minitab).

Having analyzed data, the relation was positive between inflation rate and money supply with abstract effect in accordance with economic theory. The analysis result varied concerning the rate prices and exchange price.
\end{abstract}

على الرغم من اختلاف أفكار رواد المدارس الاقتصادية، تتفق وجهات النظر

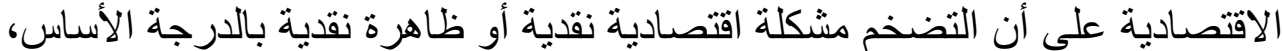

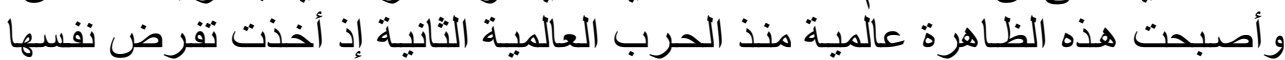

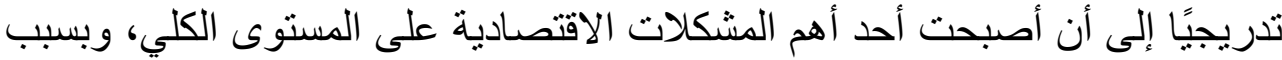

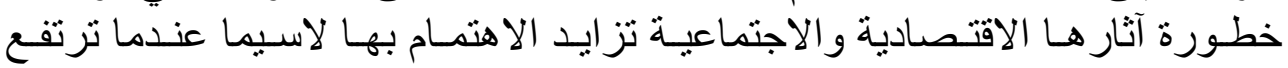
معدلاتها بشكل كبير ويصعب التحكم فيها و السيطرة عليها.

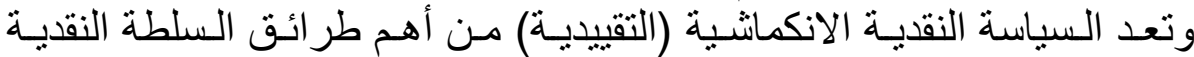

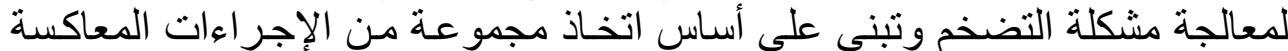

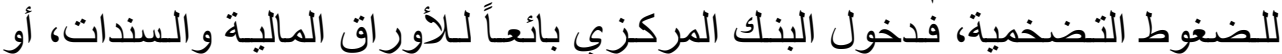

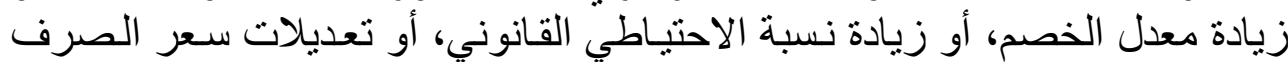

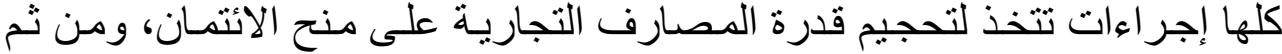
تخفيض عرض النقود، وبالتالي تخفيض مستويات الأسعار. 
وتعاني البلدان النامية من ارتفاع أسعار السلع المستوردة من الدول الرأسمالية

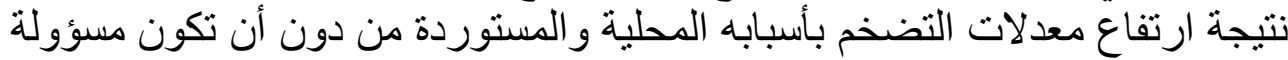

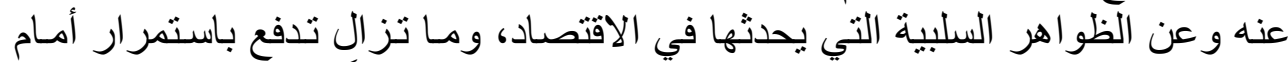

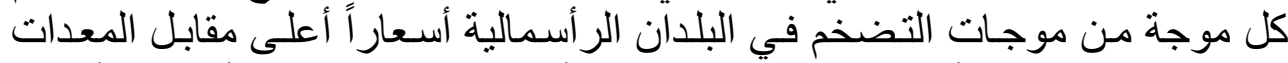

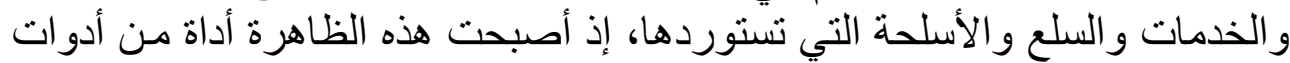

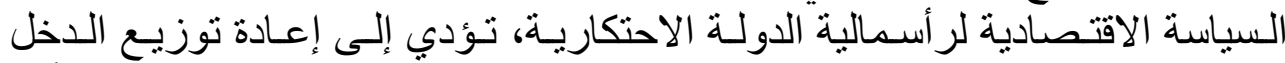

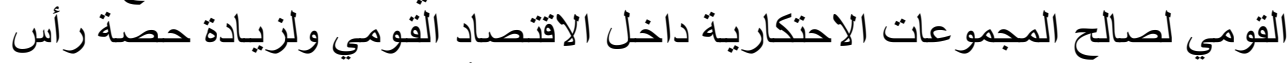

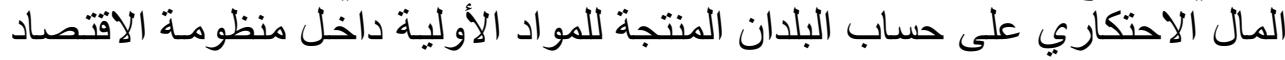

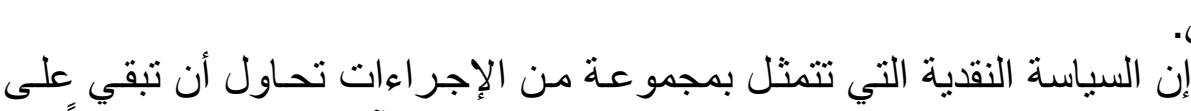

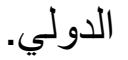

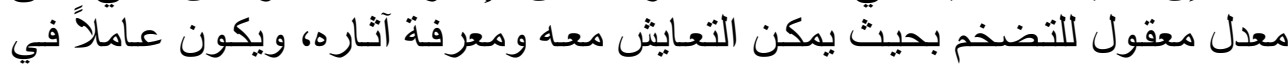

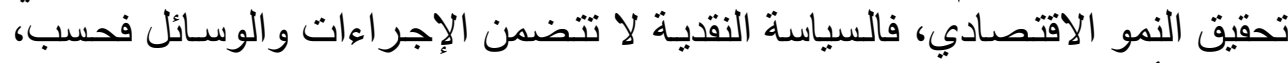

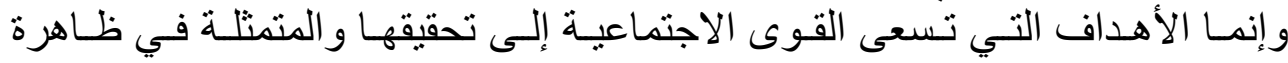

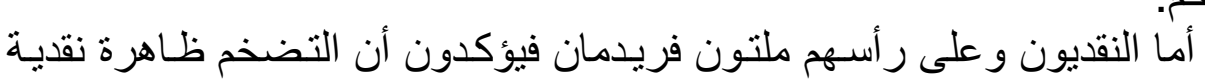

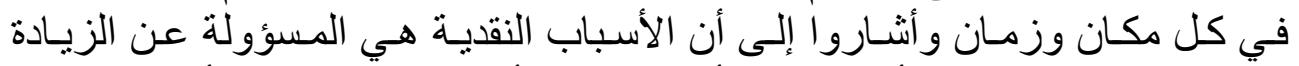

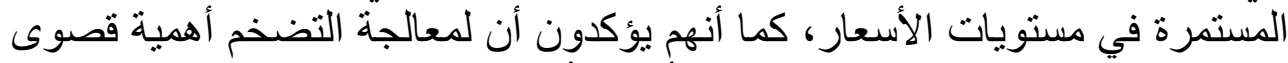

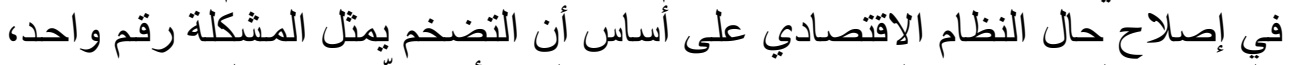

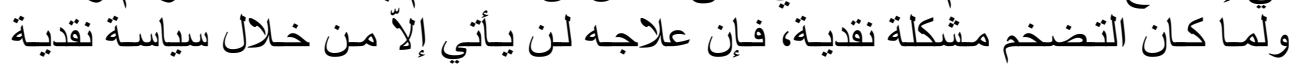

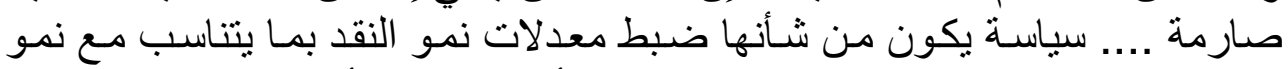

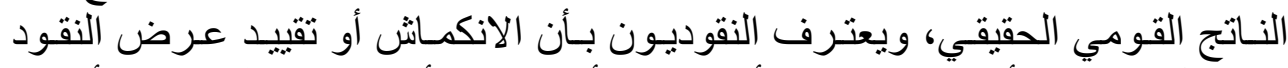

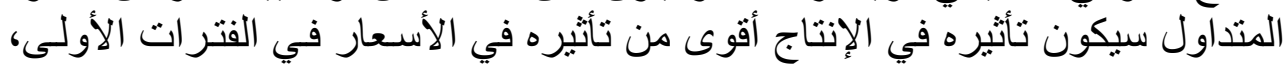

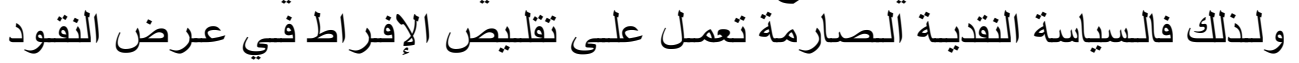
و لاسيما العجز في الموازنة العامة للاولة.

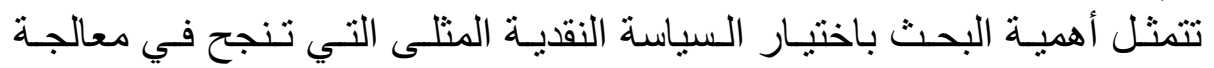

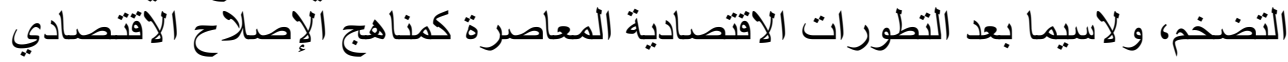

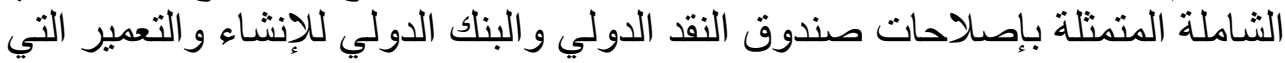

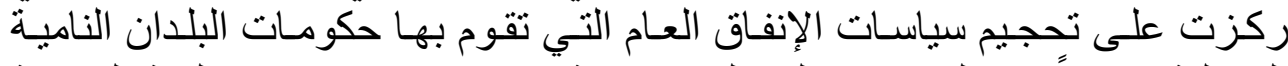

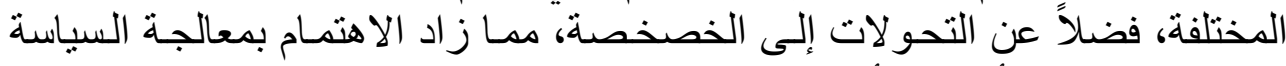

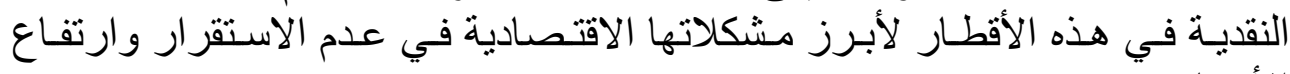

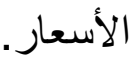




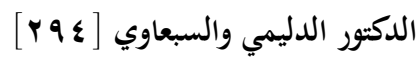

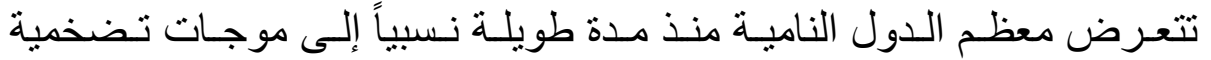

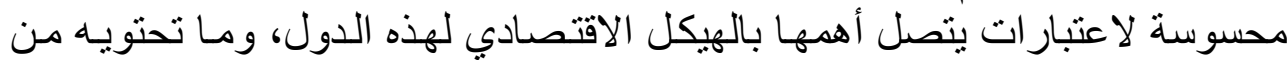

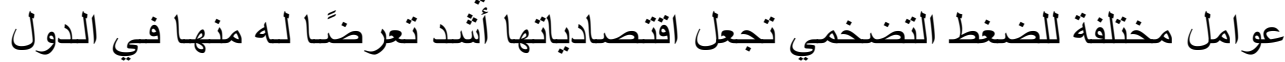

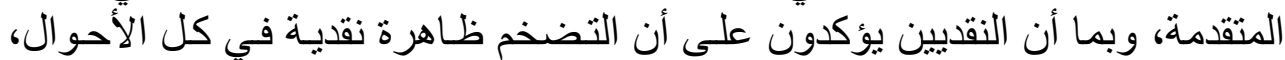

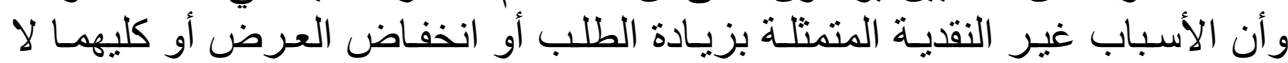

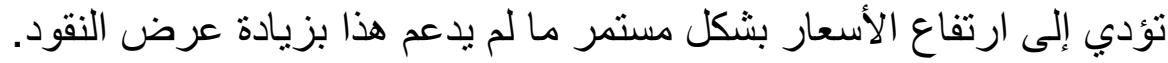

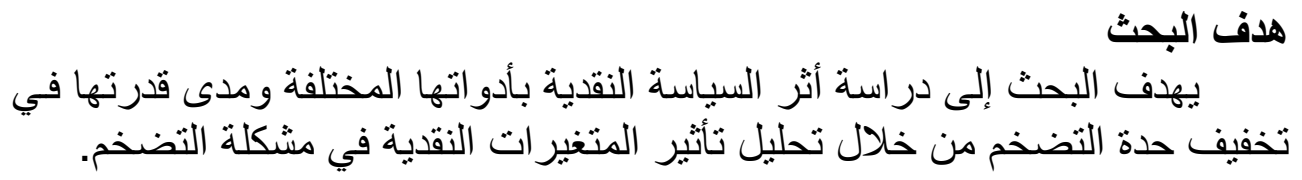

فرضية البحث

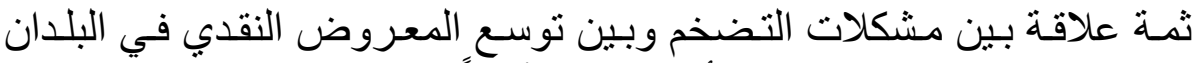

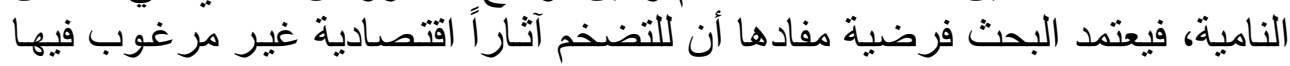

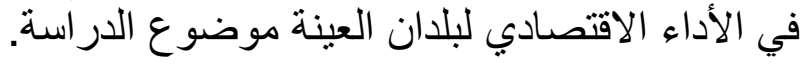

يعتمد التحليل في هذا البحث استذكار المفاهيم والأدبيات المطروحة في العقود

منهج البحث

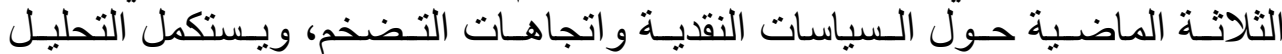

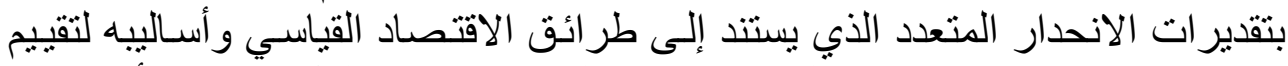

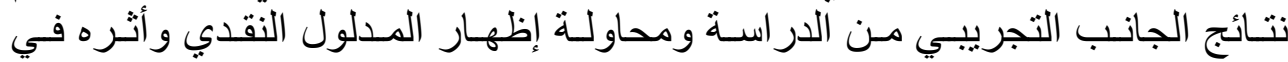

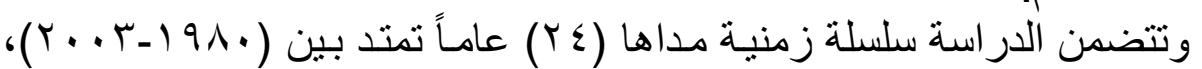
معدلات التضخم.

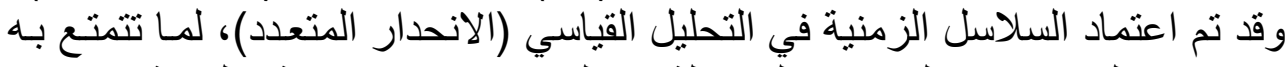

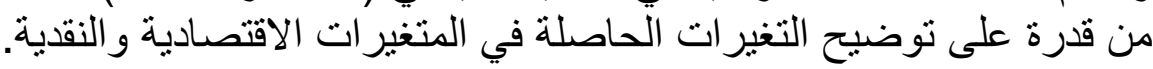

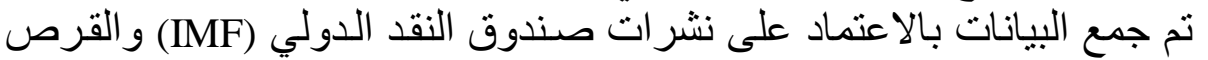

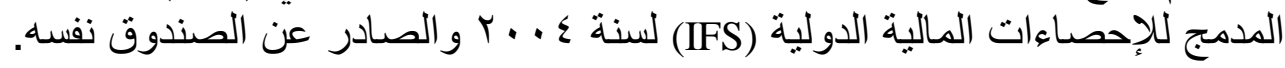

\section{مفهوم السباسة النقدية}

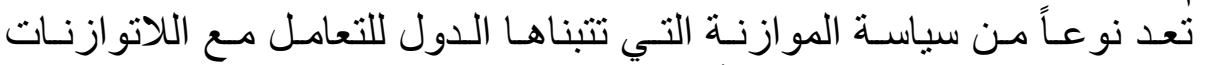

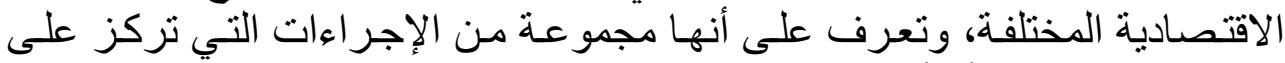

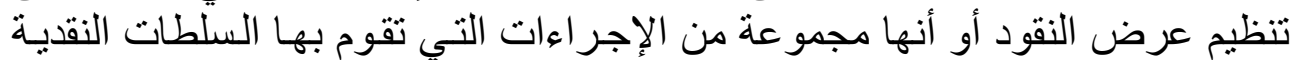

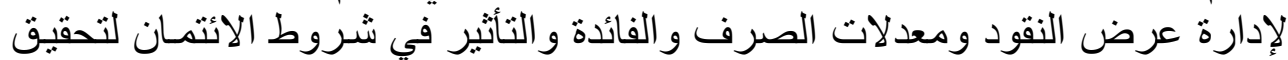

أهداف اقتصادية محددة.

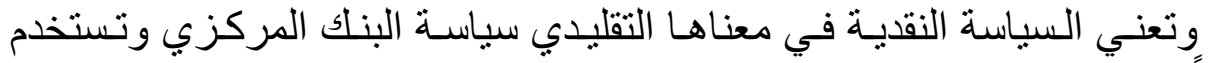

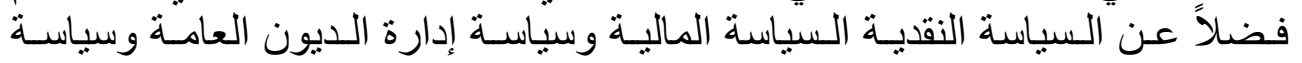
الائتمان للهيئات المالية و الحكومية. 


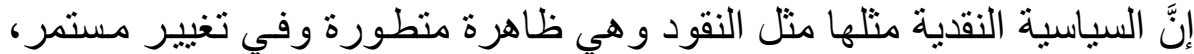

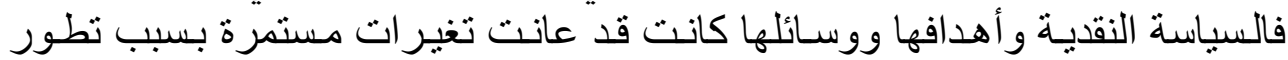

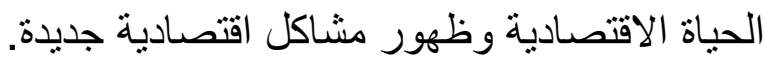

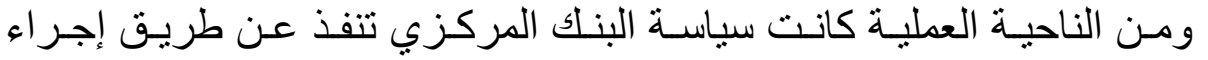

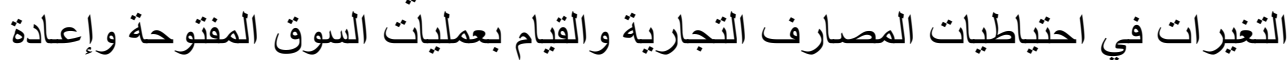

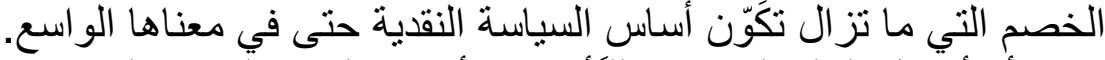

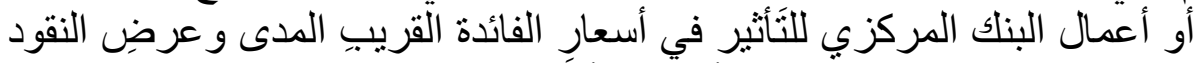

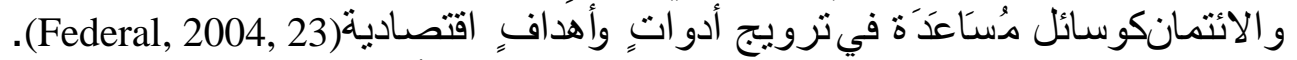
فمصطلح السياسة النقدية حديث نسبيًا إذ ظهر في أدئ أدبيات الاقتصاد في القرن

التاسع عشر (Einzing, 1964,47).

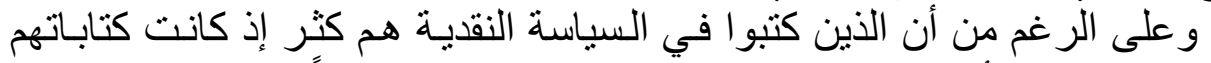

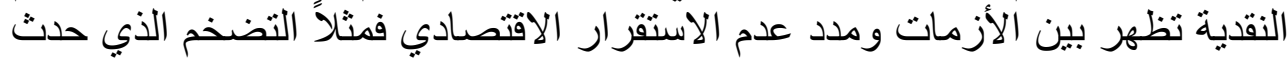

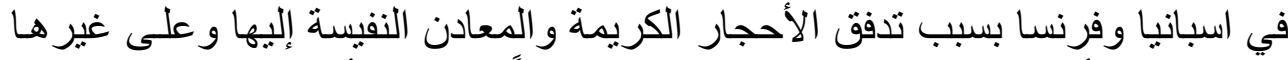

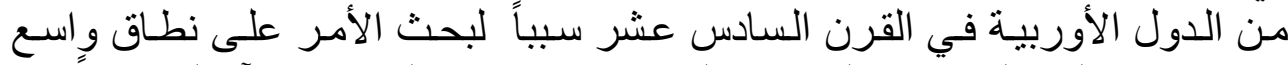

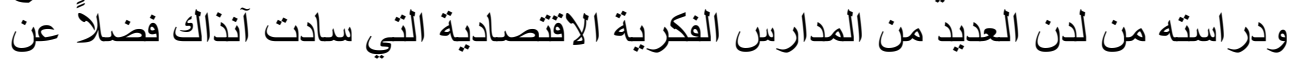

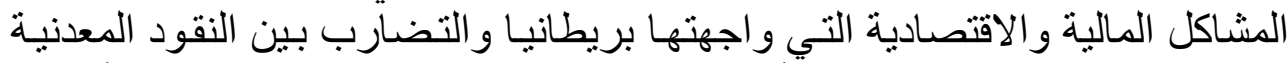

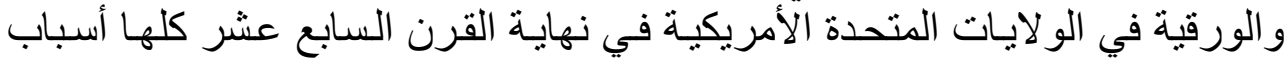

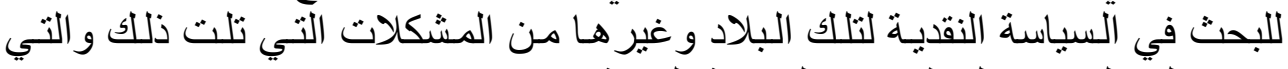
دفعت إلى البحث و التنظير في السياسة النقدية.

وتعرف السياسة النقدية بأنها استخدام عرض النيانة النقود لتحقيق أهداف اقتصادية

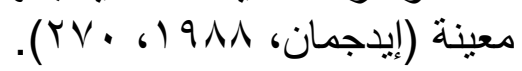

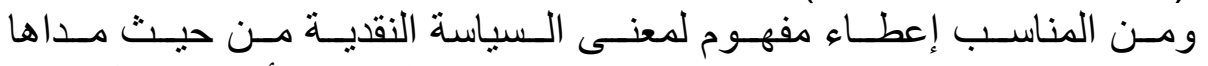

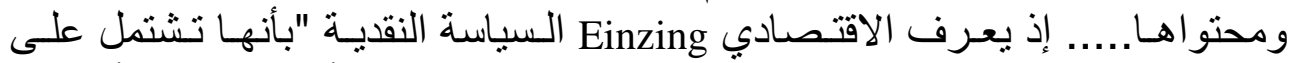

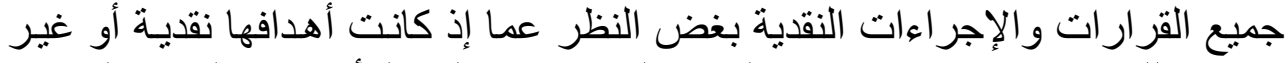
نقدية كذلك جميع الإجراءات غير النقدية التي تهدف إلى النى التأثير في النظام النقدي" .(Einzing, 1964, 50)

أما الاقتصادي النقدي G.L.Bach فيعرف السياسة النقدية بأنها "كل ما تقوم به فيه

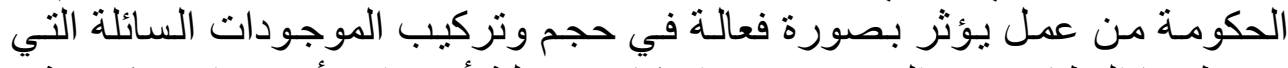

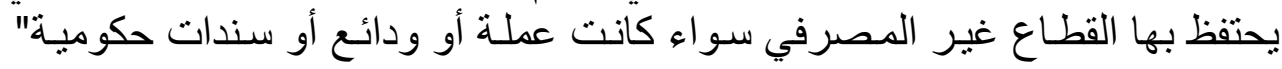
.(Bach, 1950, 35) ويعرف Kent السياسة النقديـة بأنها "إدارة التوسع و الانكماش في حجم النقد لغرض الحصول على أهداف معينة" (Kent, 1949, 417).

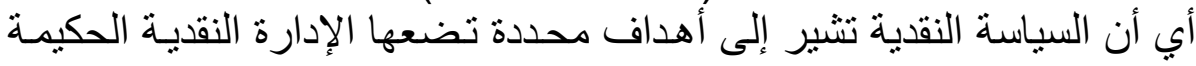

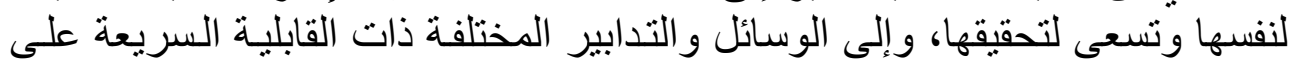
التكيف و التي يتم عن طريقها القيام بنلك الإدارة. كما عرفها الاقتصادي الهولندي J.Pen بأنها "سياسة الحكومة والبنأك المركزي بالنسبة لخلق النقود" (Pen, 1967, 149)، ومن ثم تكون السياسة النقديـة مشتملة بمـا 


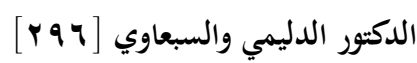

يتعلق بإصدار العملة من لدن البنك المركزي أو الخزانة المركزية (كما في الولايات

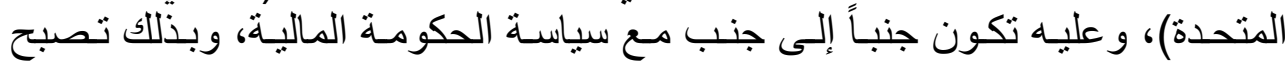
السياسة النقدية مكملة لسياسة الميز انية المئة (المالية).

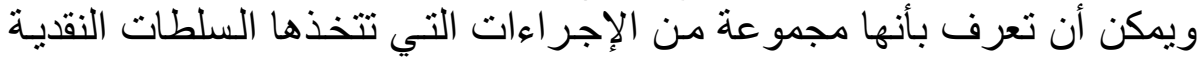

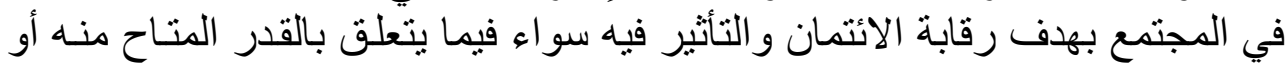

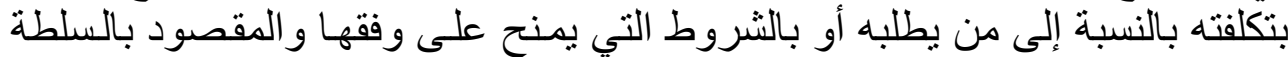

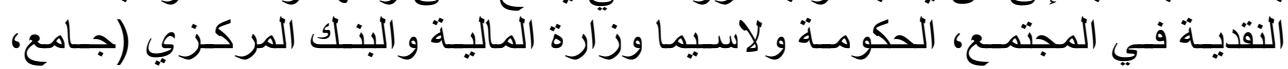
ويرى آخرون أن السياسة النقدية هي تنظيم مستوى الناتج القومي ومستوى . الأسعار عن طريق تغيير عرض آخران النقد (Ross, 1964, 327).

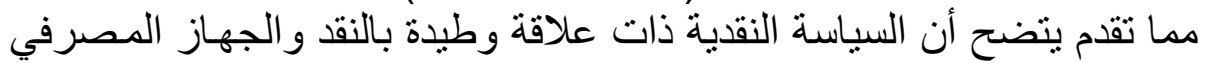

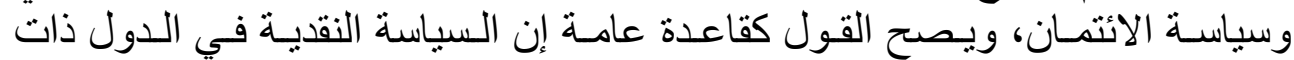

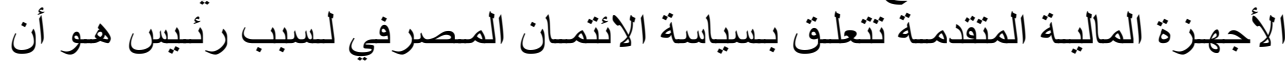

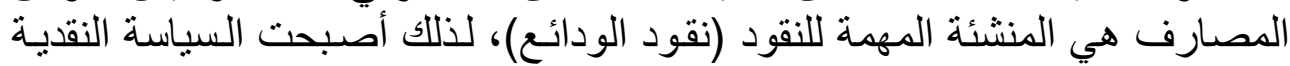
مر ادفة للسياسة الائتمانية و الرقابة على الانية الائمان.

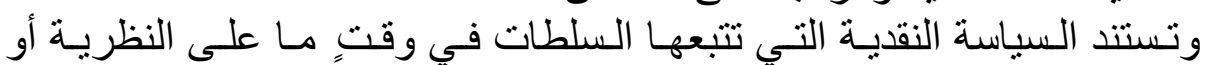

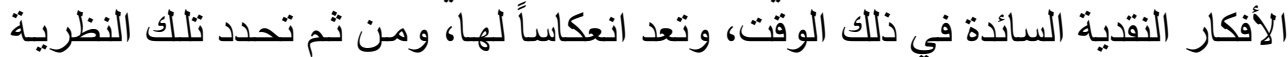

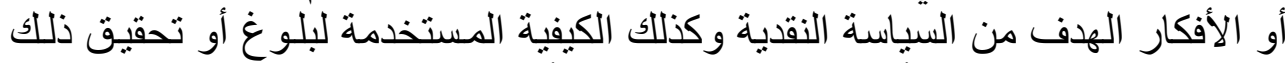

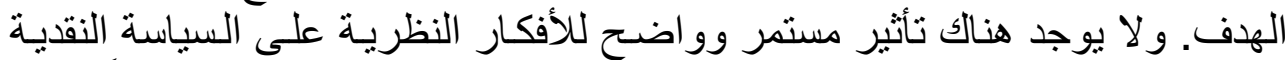

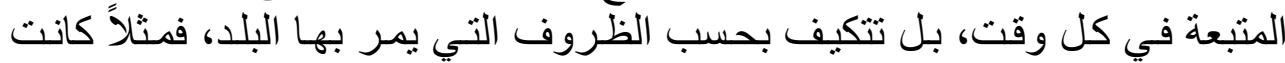

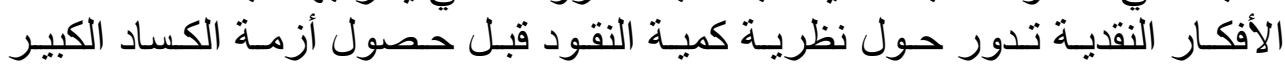

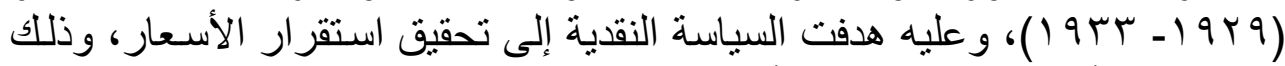

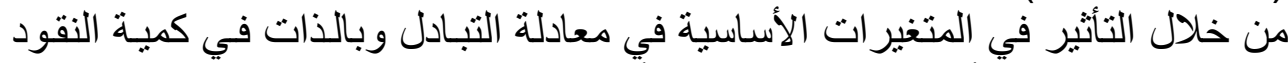
التي تعد المسؤول الأساسي عن مستوى الأسعار.

\section{متغيرات السياسة النقدية الأساسية عرض النقود}

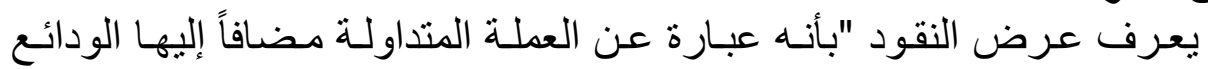

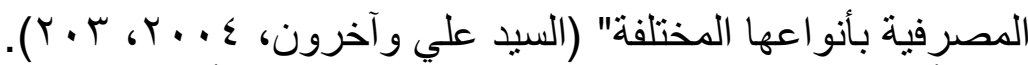

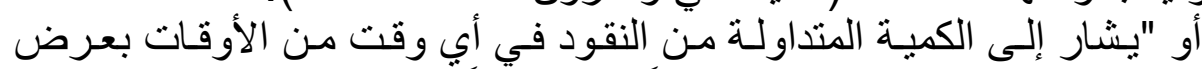

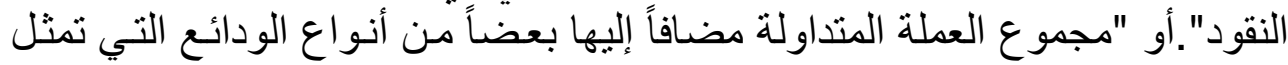

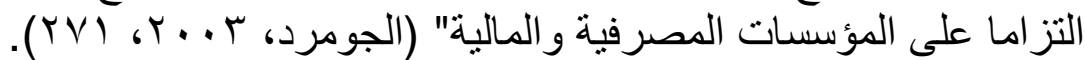

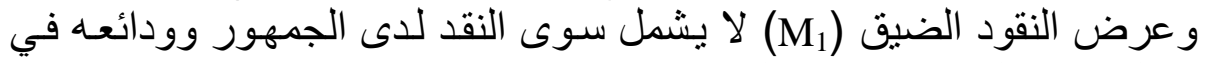

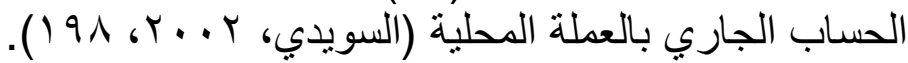

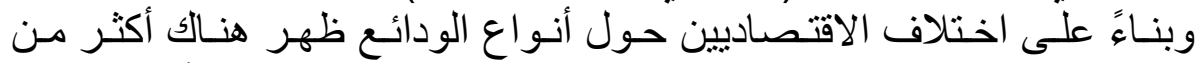

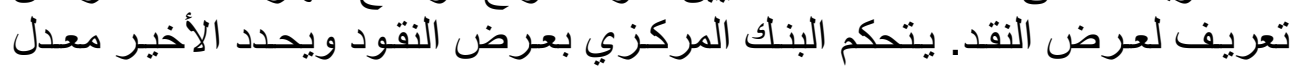
التضخم في الأمد المتوسط و الطويل (Olivier, 1997, 507). 
عرض النقود الضيق (M) = (D) = العملة المتداولة (C) + الودائع الجارية $\mathrm{M} 1=\mathrm{C}+\mathrm{D}$

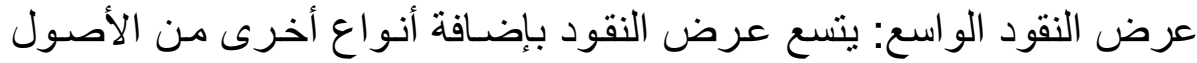

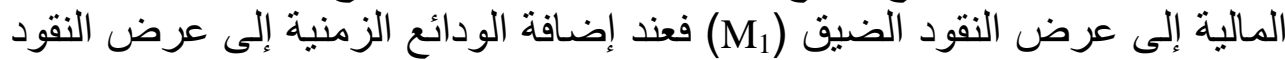

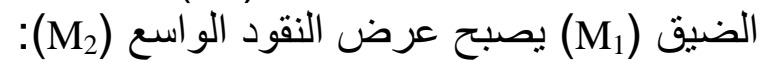

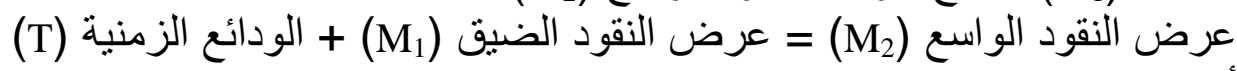

$\mathrm{M}_{1}=\mathrm{C}+\mathrm{D}$

$\mathrm{M}_{2}=\mathrm{C}+\mathrm{D}+\mathrm{T}$

$\mathrm{M}_{2}=\mathrm{M}_{1}+\mathrm{T}$

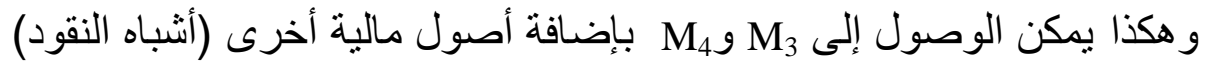

أقل سيولة من العملة المنداولة أو الجارية.

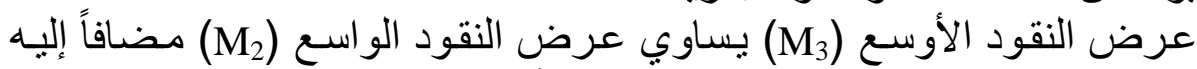

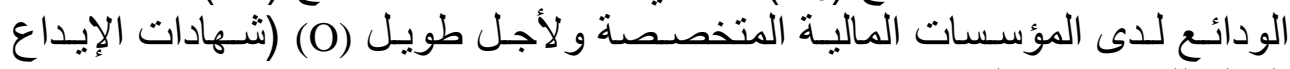

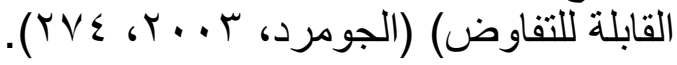

$\mathrm{M}_{3}=\mathrm{M}_{2}+\mathrm{O}$

، إن عرض النقود يعتمد على خمسة عو امل هي (السيد علي وآخرون، ع ....T،

العوامل المؤثرة في عرض النقود $:(r \cdot \Lambda-r \cdot 0$

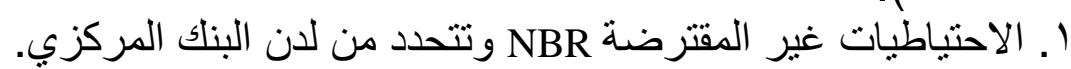

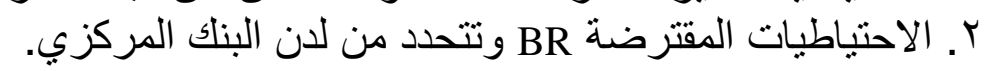

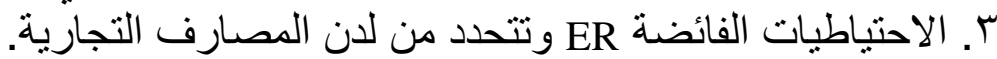

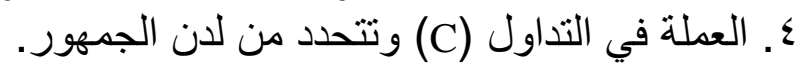

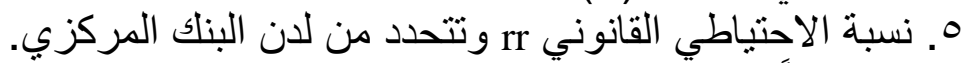

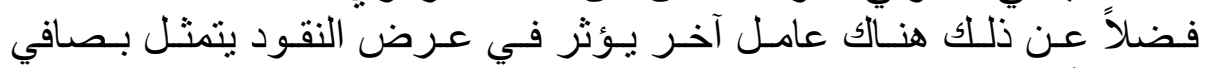

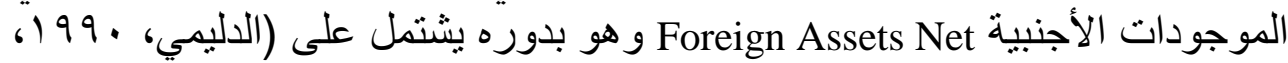

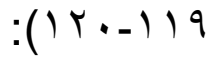
ا ا. العملات الأجنبية القابلة للتحويل. r. r. الذهب النقدي.

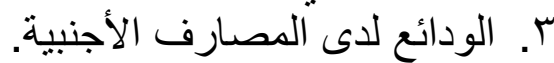

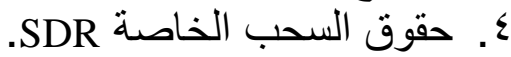
×. هركز الاحتياطي في صندوق النقد الدولي.

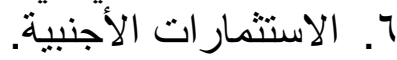

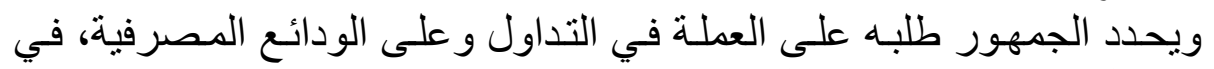

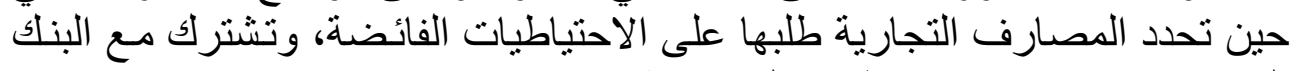
المركزي في تحديد الاحتياطيات المقترضة. 


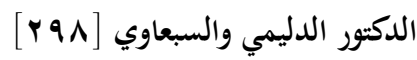

وبما أن هناك علاقة بين عرض النقود و المستوى العام للأسعار، فالزيادة في

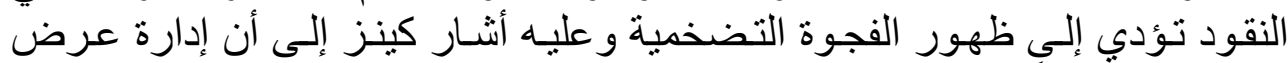

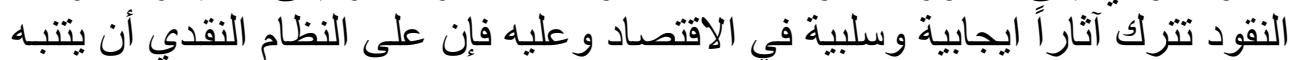

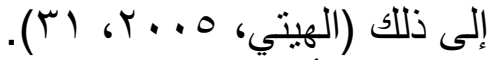

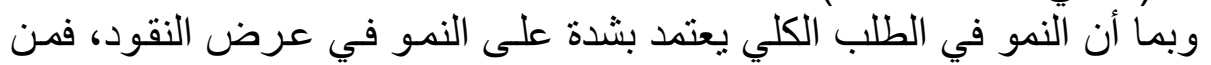

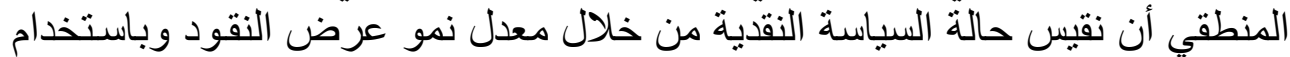

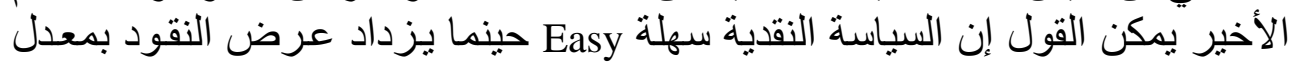

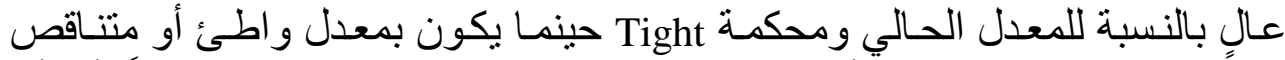

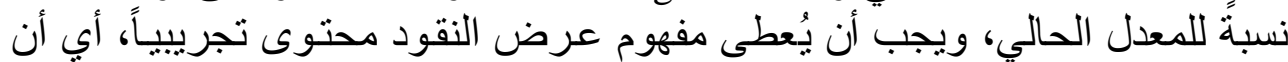

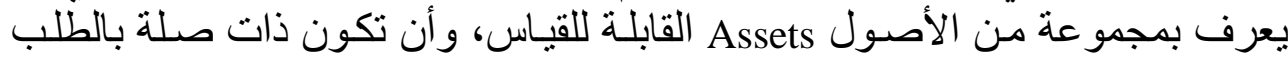

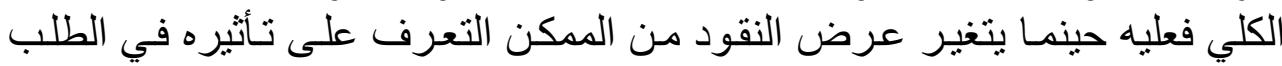

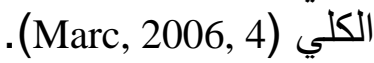

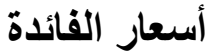

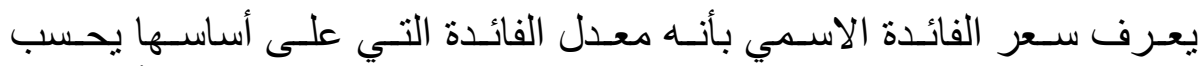

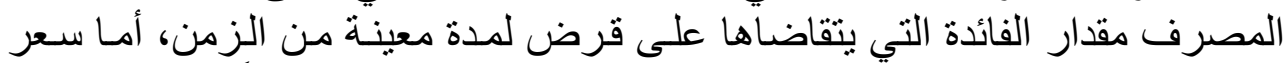

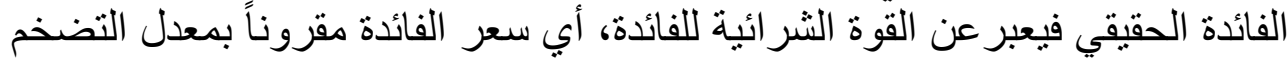

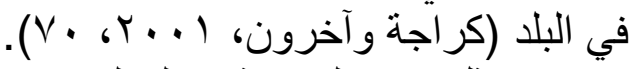

ويمثل سعر الفائدة ثمن التخلي عن النقود ألو أو رأس المـال، وتستعمله الدولية أداة

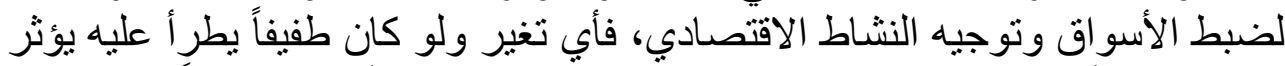

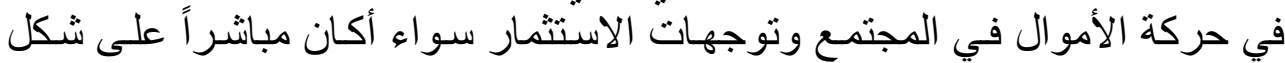
مشروعات أم غير مبانشر في الأوراق المالية.

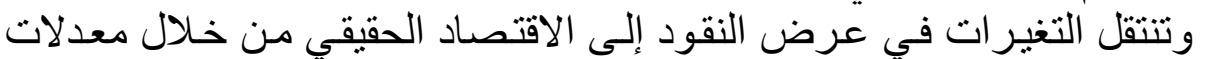

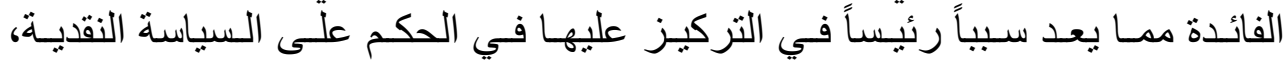

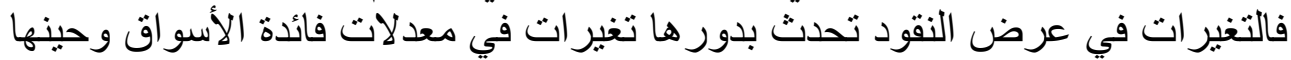

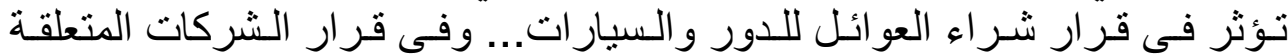

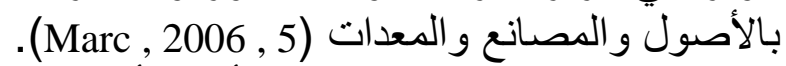

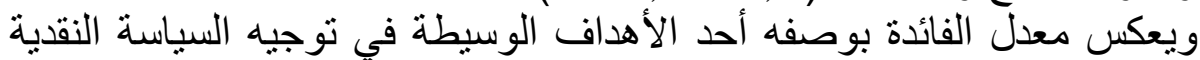

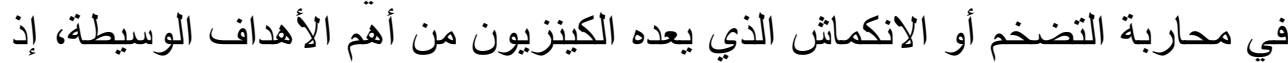

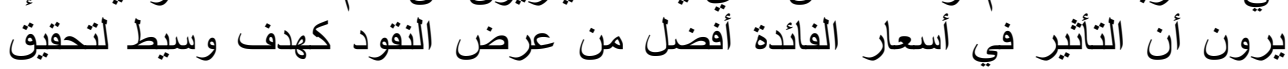

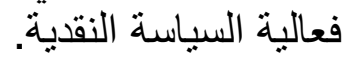

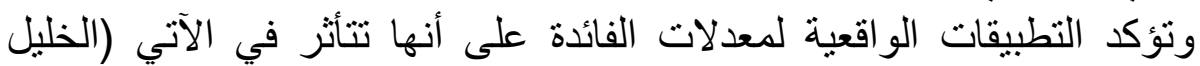

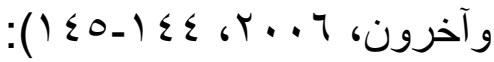

$$
\begin{aligned}
& \text { ا ا. متطلبات الو اقع الاقتصادي من ركود والن وازدهار. }
\end{aligned}
$$

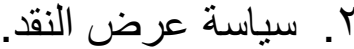

$$
\begin{aligned}
& \text { ب. ب. سياسة الائتمان النافذة. } \\
& \text { ع. السياسة الضريبية من حيث معدل الضر ائب ومدى عدالة عبئها. }
\end{aligned}
$$




$$
\begin{aligned}
& \text { ه. مستوى التشغيل (معدلات البطالة). }
\end{aligned}
$$

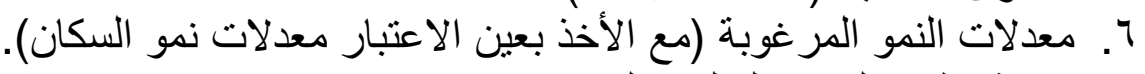

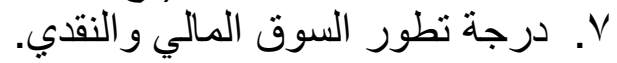

$$
\begin{aligned}
& \text { A. . معدلات التضخم السائدة. }
\end{aligned}
$$

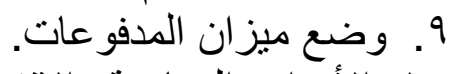

$$
\begin{aligned}
& \text { • . . الأهداف السياسية والاقتصادية والاجتماعية المرغوبة. }
\end{aligned}
$$

اختيار أسعار الفائدة الحقيقية السلبية

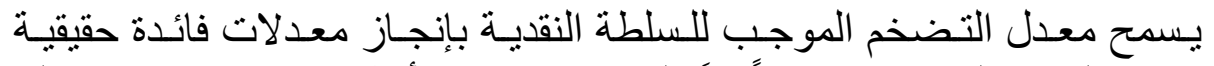

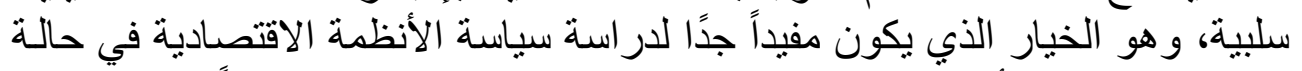

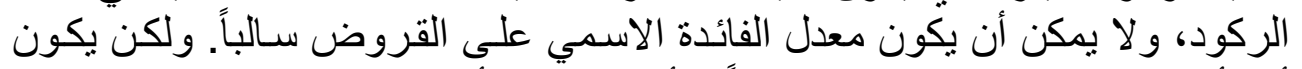

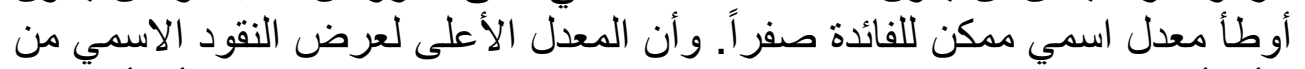

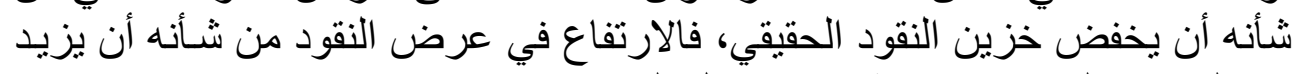

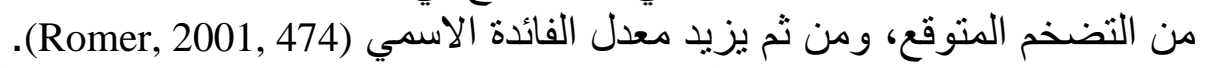

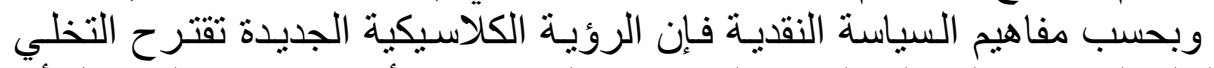

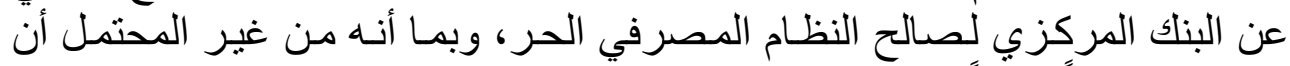

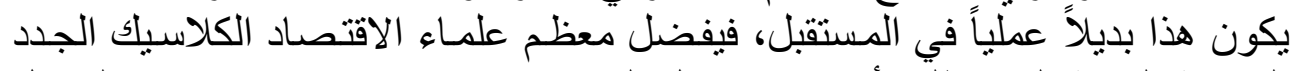

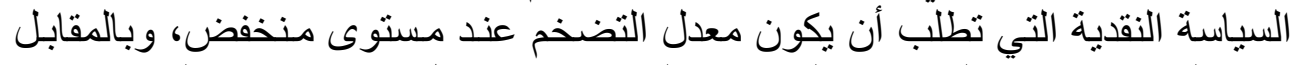

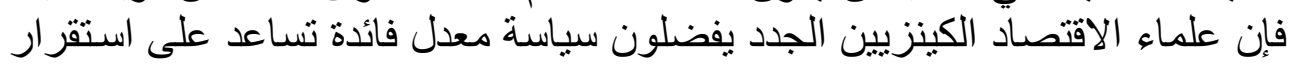

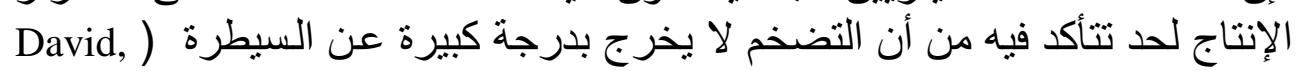
. (2005, 205

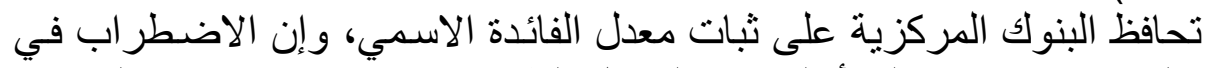

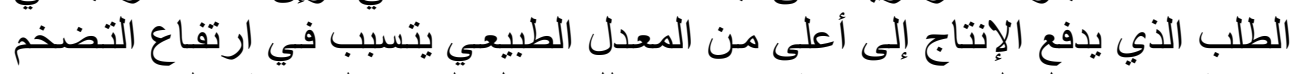

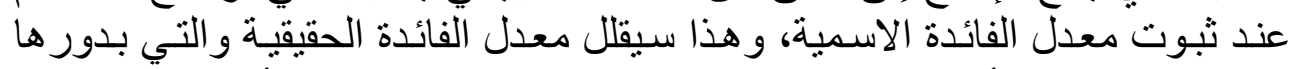

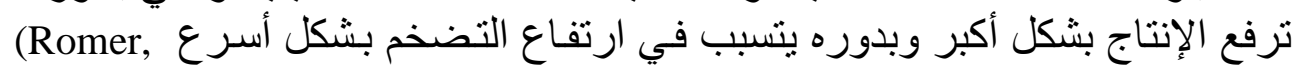

$$
\text { .2001, 500-501) }
$$

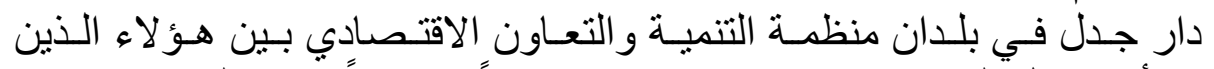

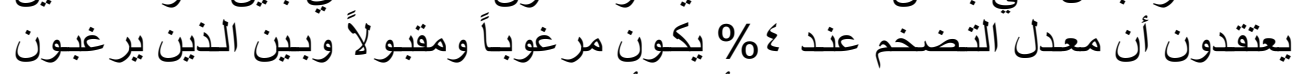

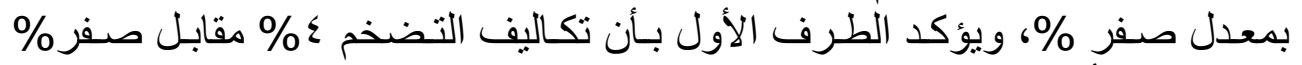

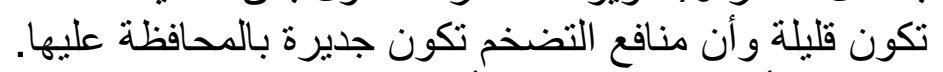

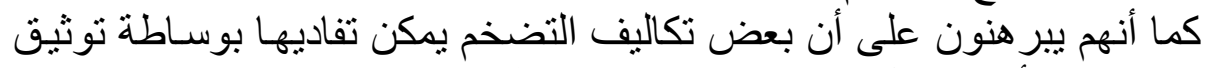

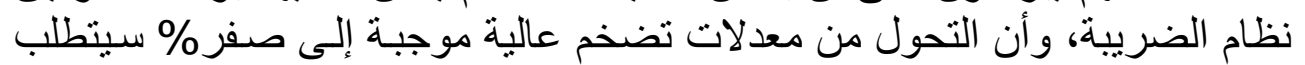

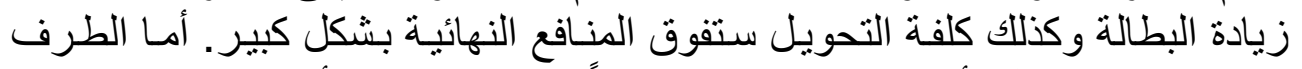

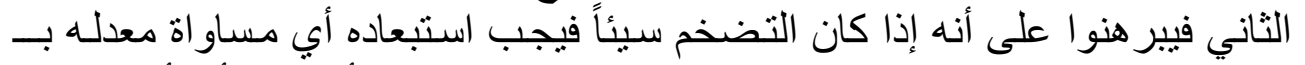
صفر\% ويعد الهدف المفضل لهم على إذى جميع المعدلات الأخرى، أبي أنسه يناظر 


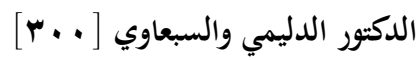

استقرار الأسعار ويكون السعر معروفاً اليوم وبعد عشر سنوات أو عشرين سنة....

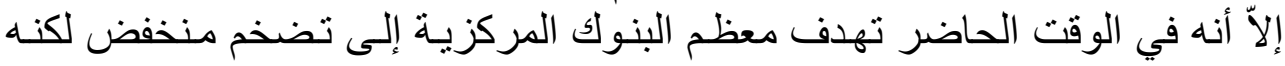

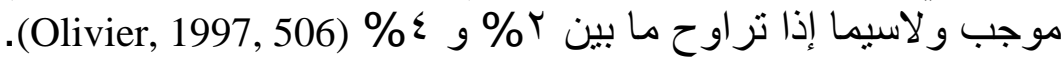

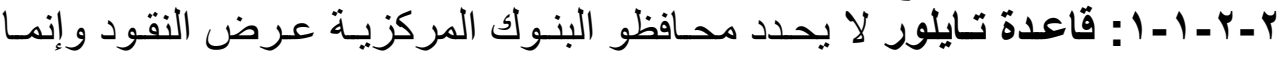

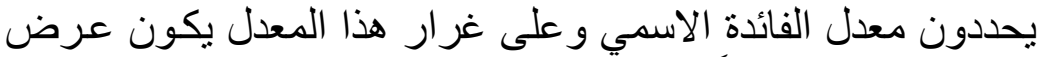

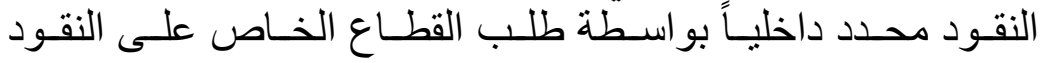

.(David, 2005, 203)

فحينما يختار البنك المركزي هدفاً ويعلن عنه وكان هذا الهذف هو تحقيق معدل

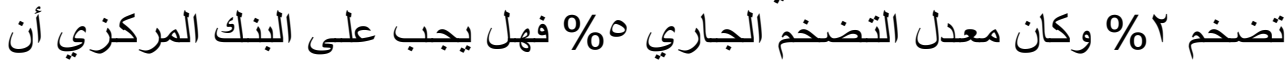

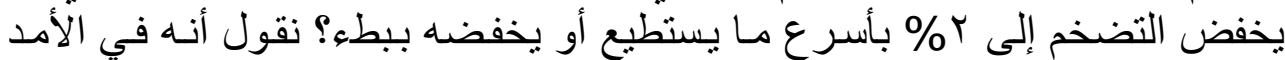

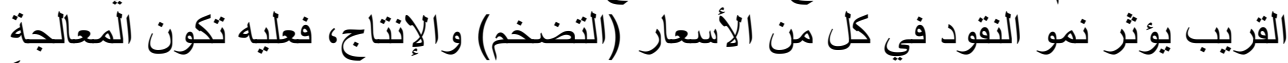

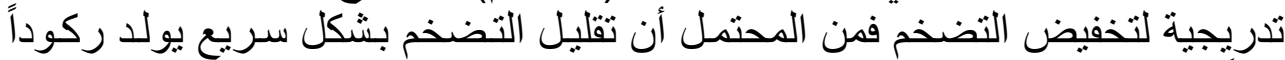

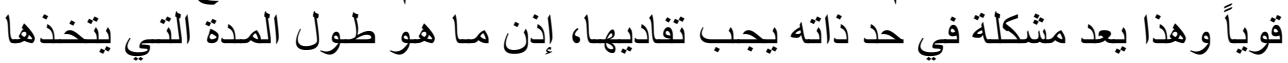

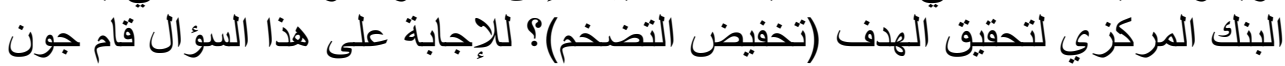

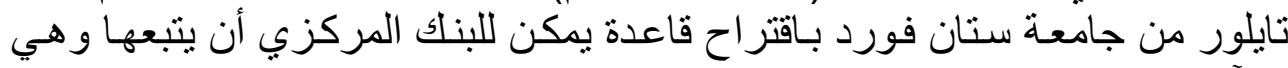

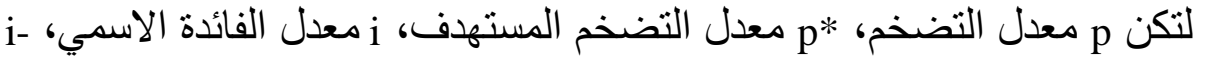

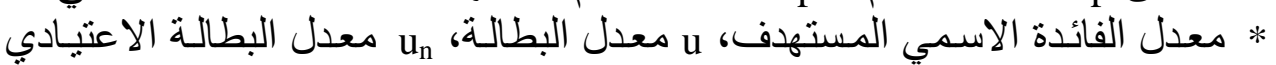
(الطبيعي) و اثبت تايلور أن البنك المركزي يجب أن يتبع القاعدة الآتية: $i=i^{*}+a\left(p-p^{*}\right)-b\left(u-u_{n}\right)$

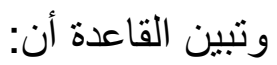

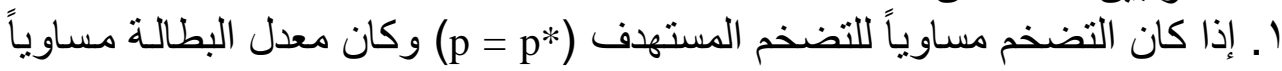

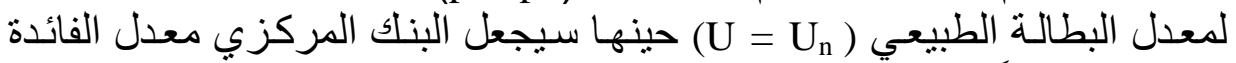

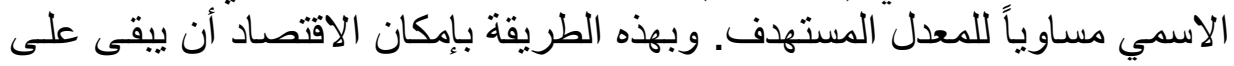

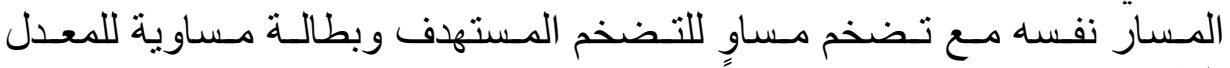

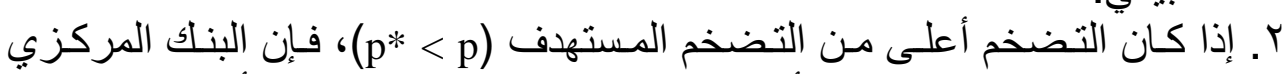

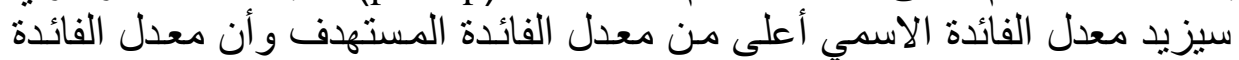

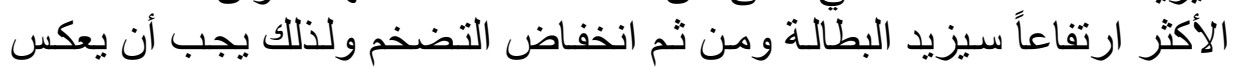

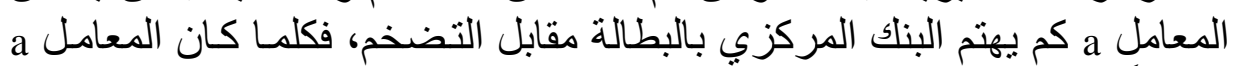

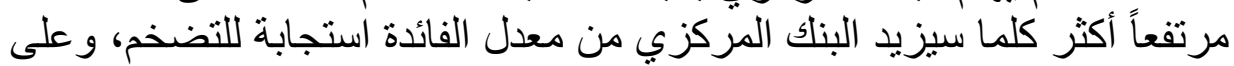

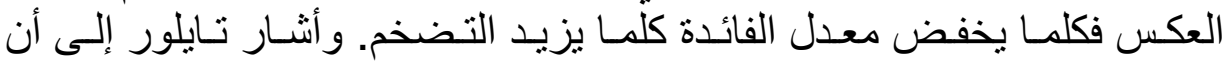

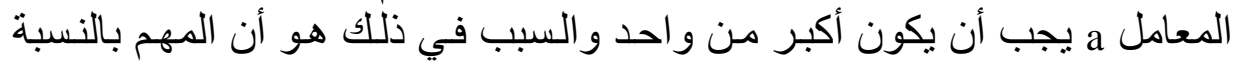

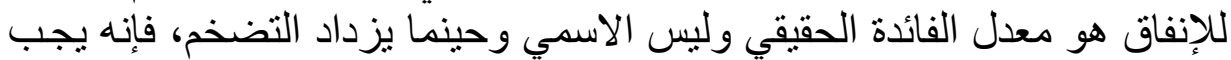

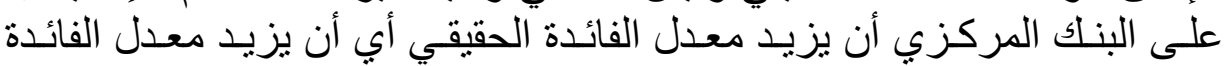
الاسهي أكثر من واحد مقابل واحد مع التضخم. 


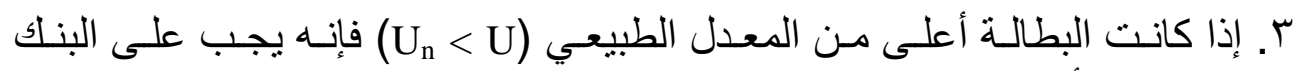

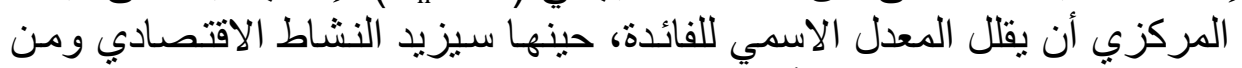

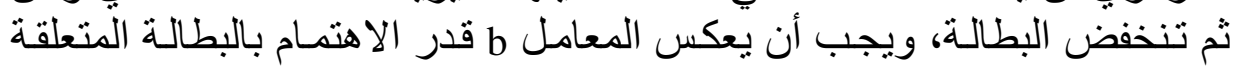

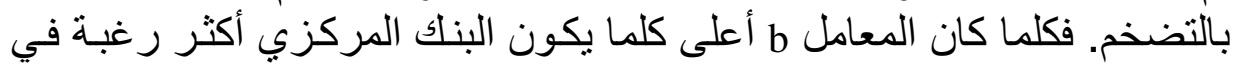

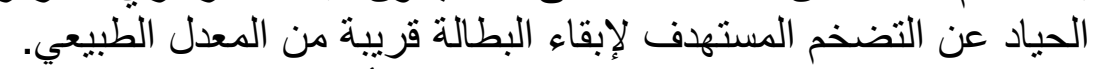

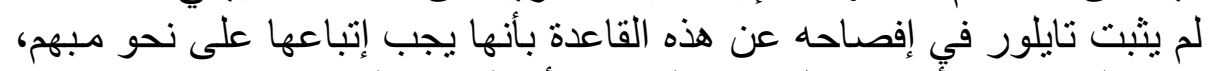

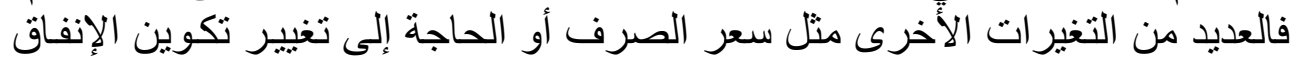

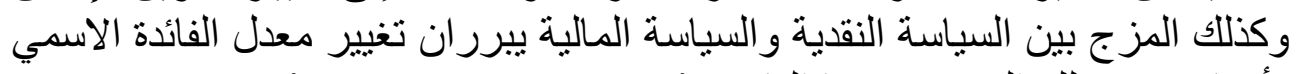
لأسباب غير تللك التي تضمنتها القاعدة (Olivier, 1997, 509-510).

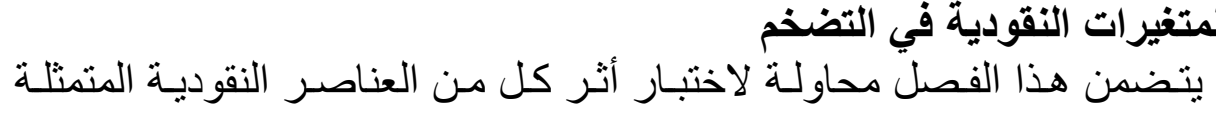

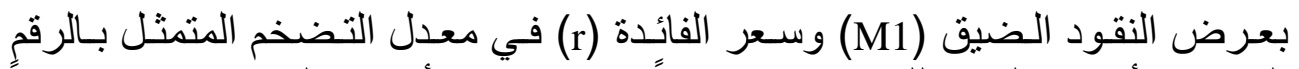

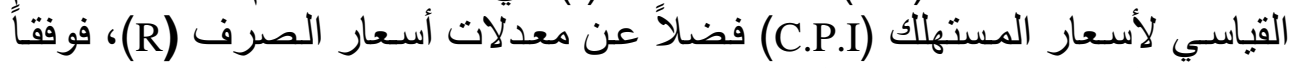

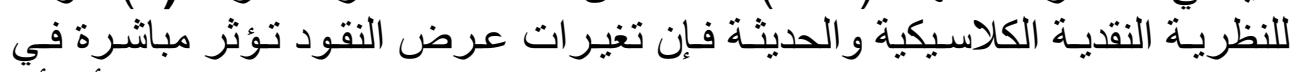

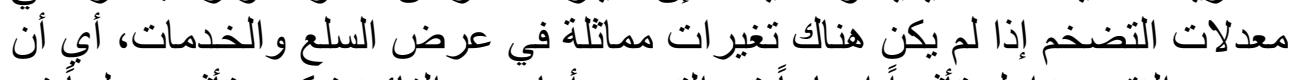

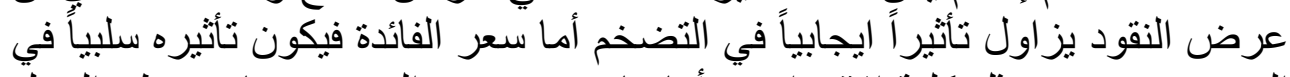

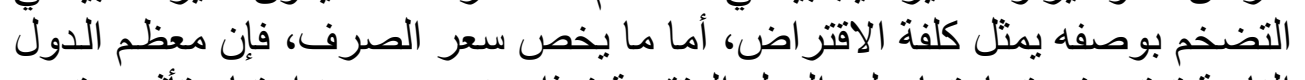

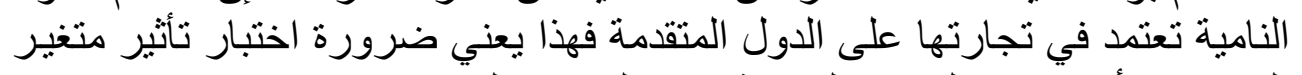
الصرف الأجنبي في التضخم لمعرفة حجم التضان التفم المستورد.

توصيف الأنموذج القياسي المستخدم في التقدير

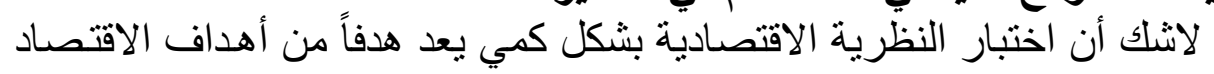

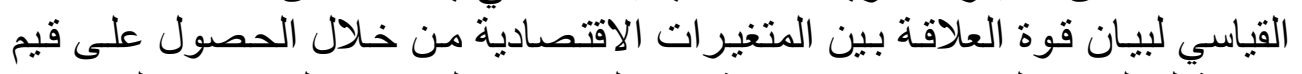

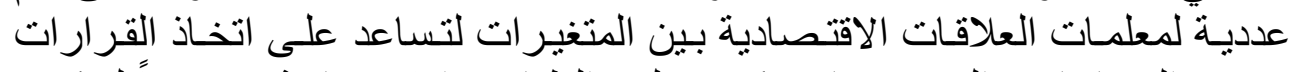

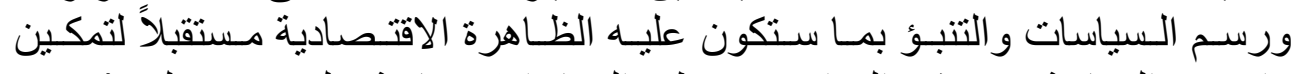

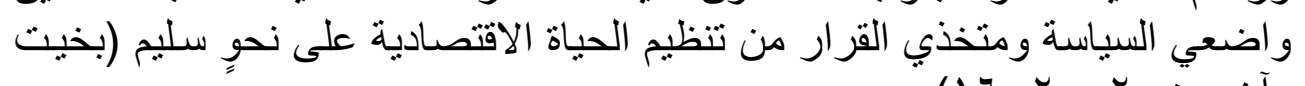

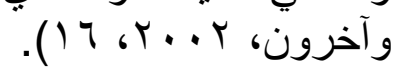

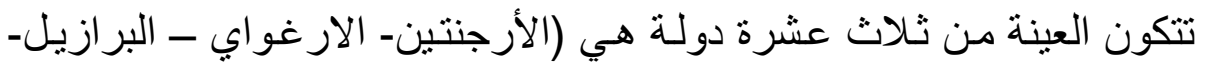

حجم العينة

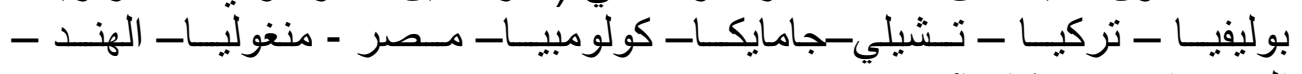
الهندور اس- هنكاريا) 


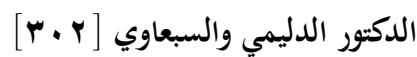

$$
\mathrm{Y}_{\mathrm{i}}=\mathrm{B}_{\mathrm{o}}+\mathrm{B}_{1} \mathrm{X}_{1 \mathrm{i}}+\mathrm{B}_{2} \mathrm{X}_{2 \mathrm{i}}+\mathrm{B}_{3} \mathrm{X}_{3 \mathrm{i}}+\mathrm{e}_{\mathrm{i}}
$$

المتغير المعتمد: الرقم القياسي لأسعار المستهلك Consumer Prices Index بوصفه اعنه

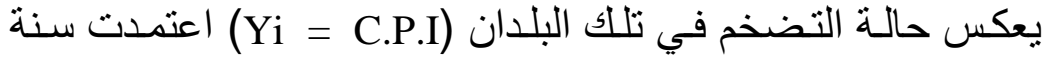

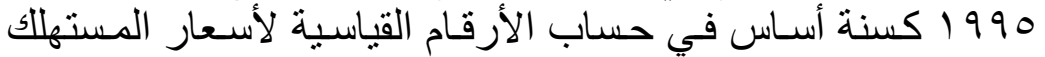
CPI

r. المتغيرات المفسرة (التوضيحية)

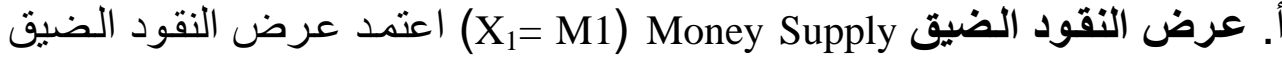

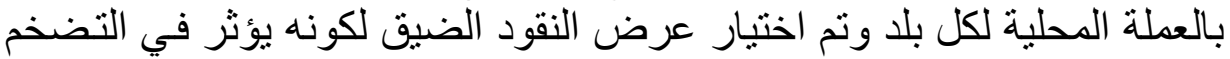
أكثر من غيره بسبب كبر حجم العملة في التداول في البلدان النامية.

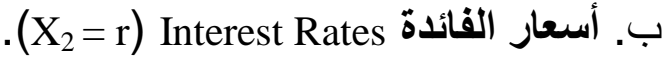
ج. معدلات الصرف

وبعد الاختبار القياسي المتمثل بالرسم البياني للبيانات والتوزيع الطبيعي تبين

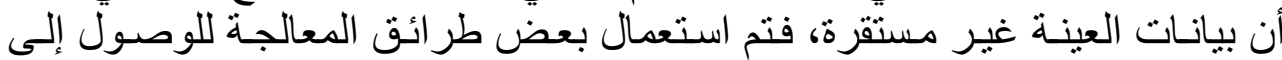

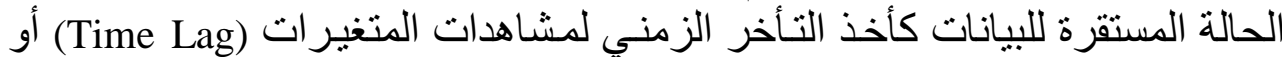

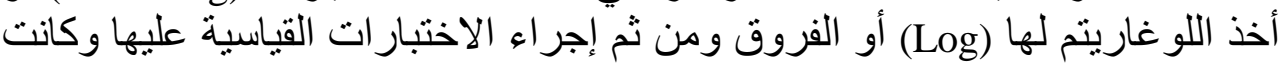

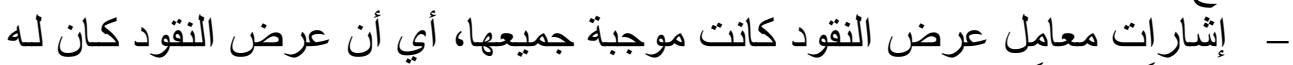

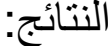

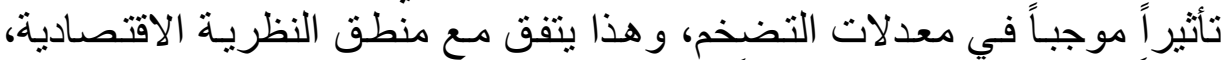

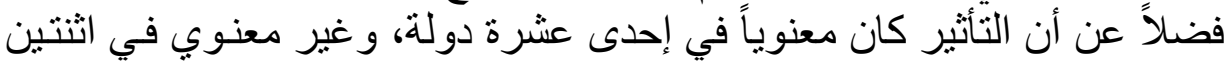

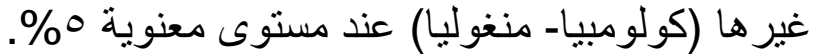

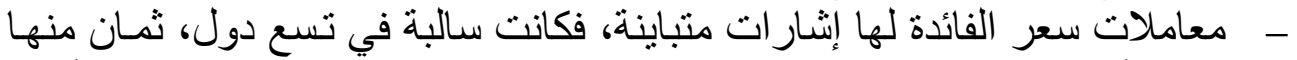

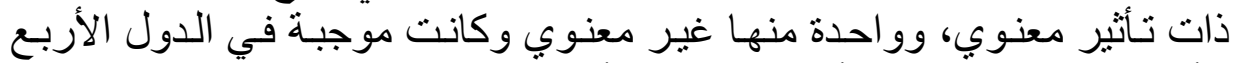

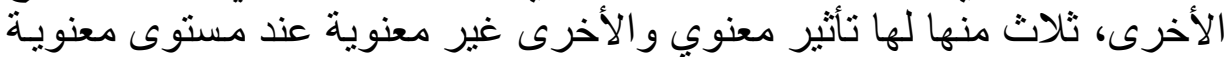
$\% \circ$ - أما معاملات معدل الصرف فكانت موجبة في تسعة بلدان، وكان التأثنير معنوي

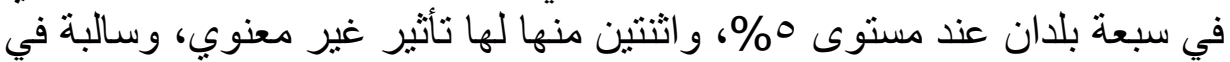

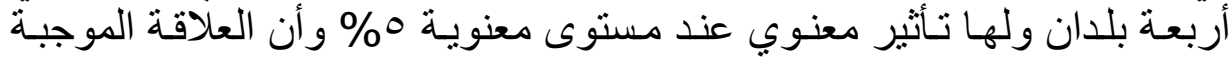

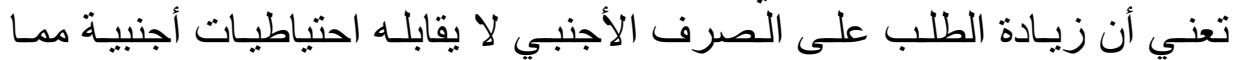
يؤدي إلى ارتفاع سعر الصرف الأجنبي أبي انخفاض قيمة الإن العملة الوطنية ومن ثم

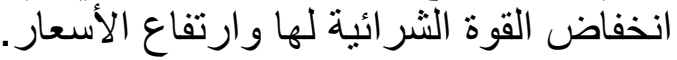

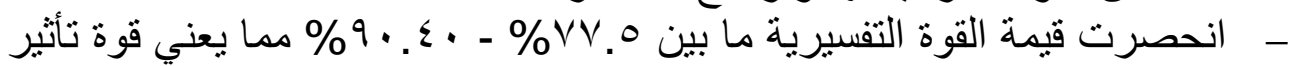

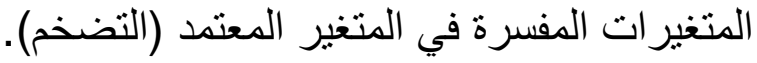


- كان الأنموذج القياسي معنوياً بالنسبة لبلدان العينـة جميعها إذ كانت F المحتسبة

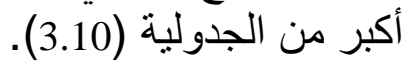

Argentina 2 الأرجنتين

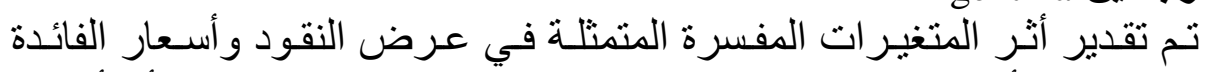

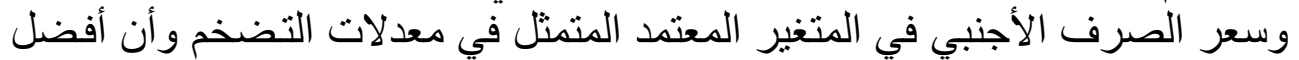

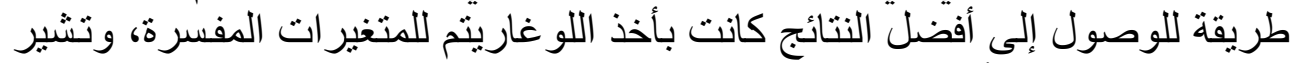

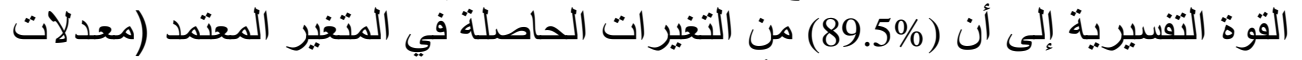

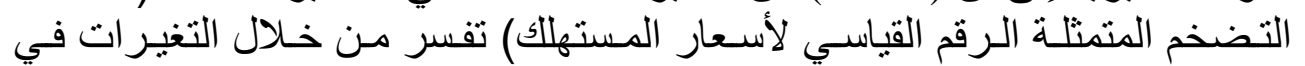

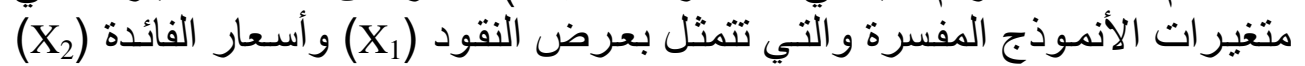

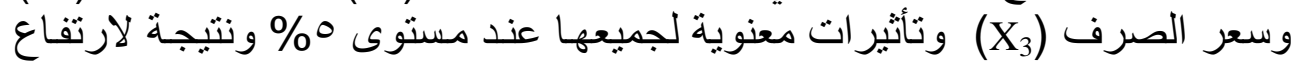

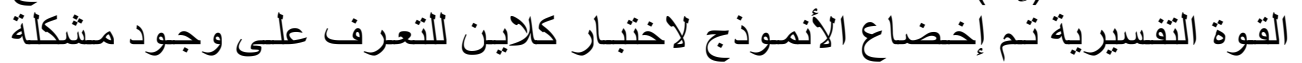

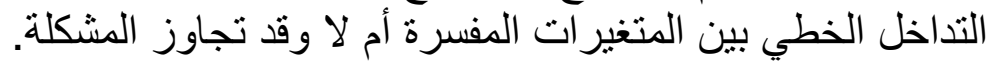

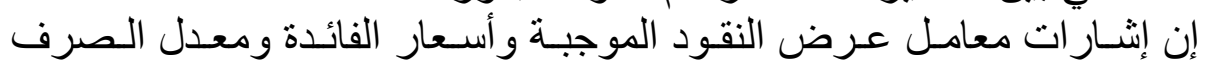
السالبة تتفق وفرضية البحث و النظرية الاقتصادية.

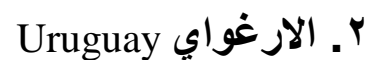

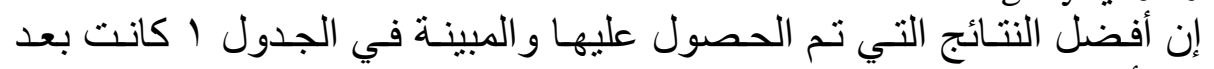

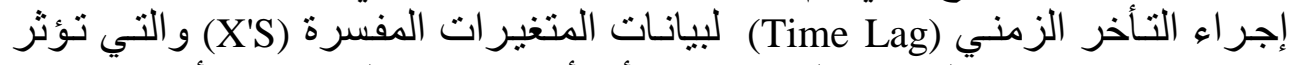

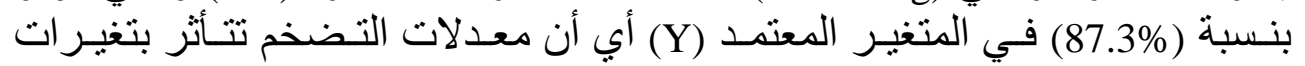

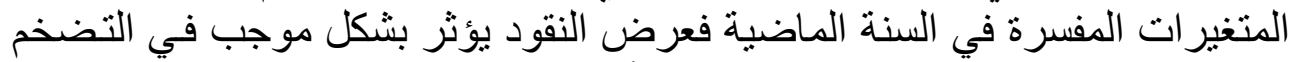

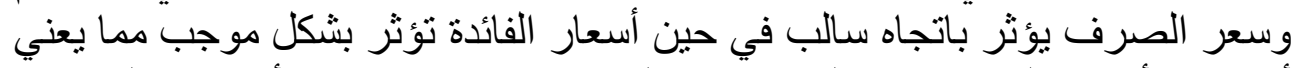

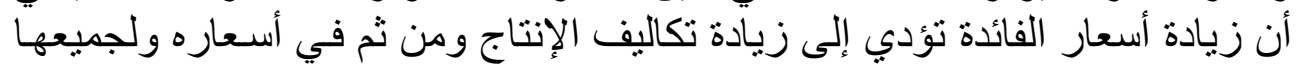

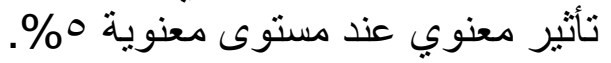

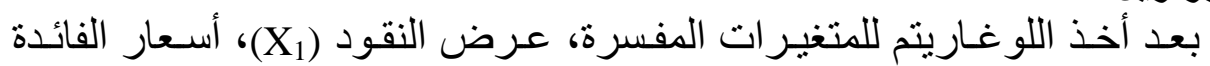

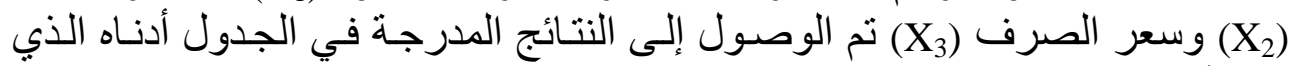

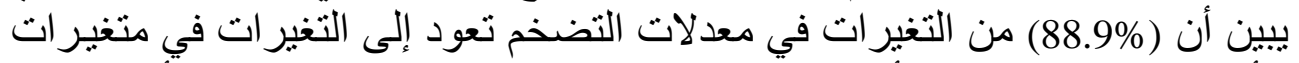

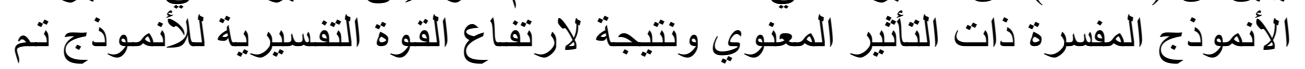

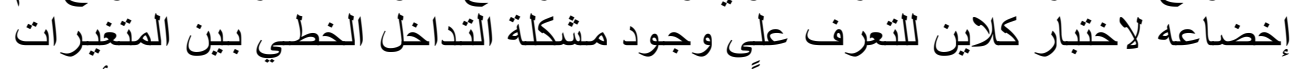

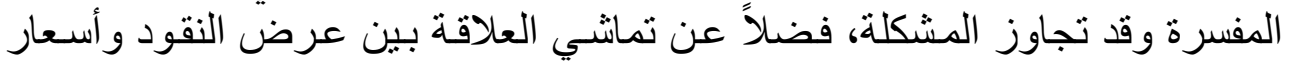

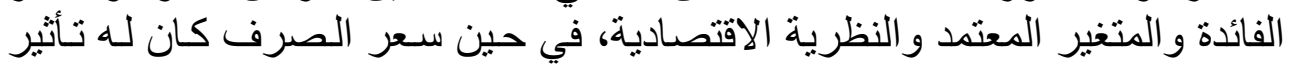

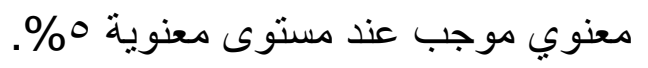

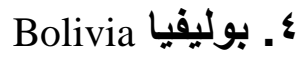




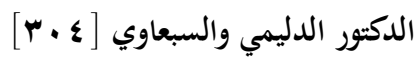

بعد أخذ التأخر الزمني (Time Lag) للمتغير المعتمد كانت القوة التفسيرية

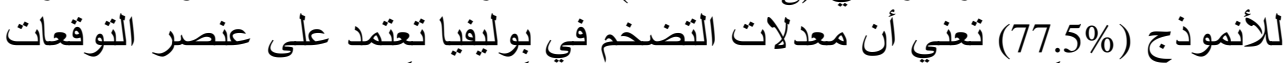

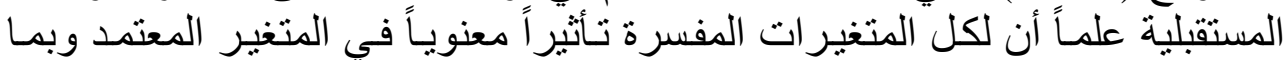

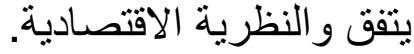

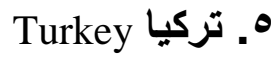

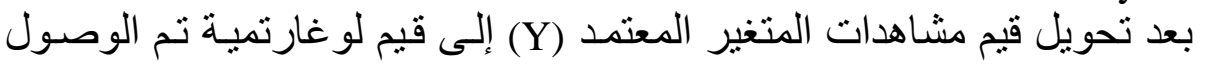

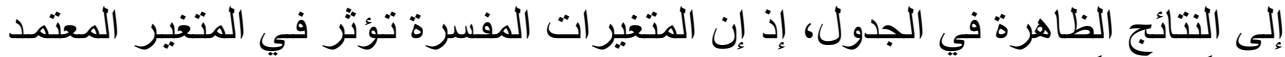

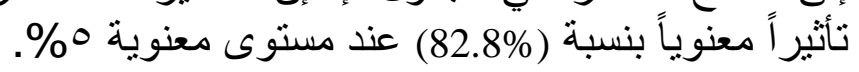

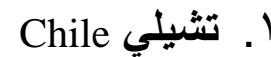

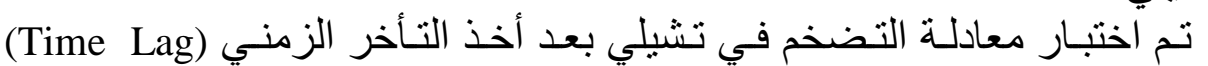

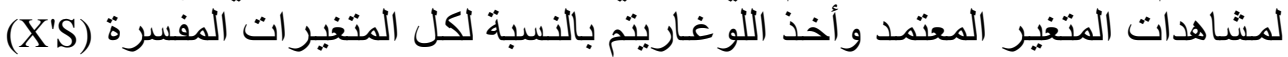

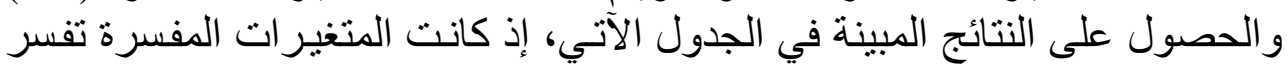

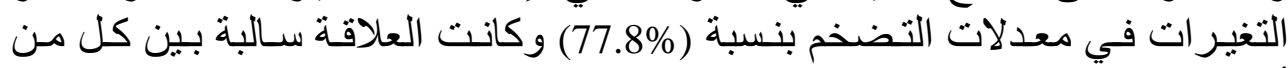

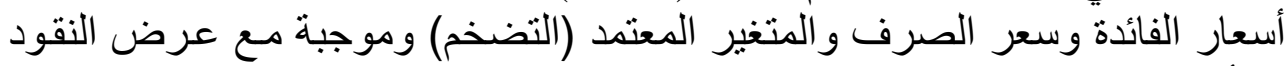

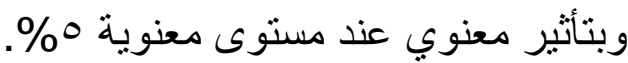

لغرض اختبار أثر المتغيرات المفسرة في المتغير المعتمد تم أخذ اللوغاريتم

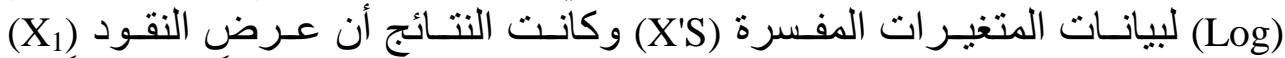

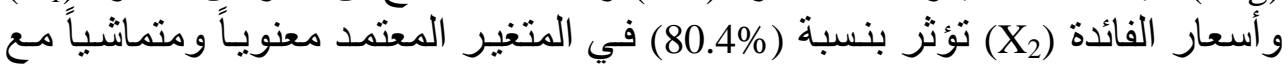
النظرية الاقتصادية، ولم تظهر معنوية سعر الصرف (X) لعدم) لعدم تجاوز الاختبارات

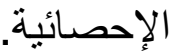

1. كولومبيا Colombia

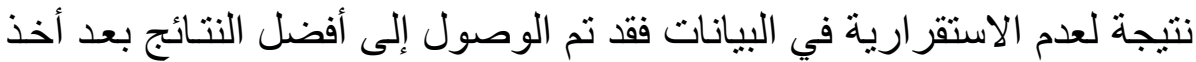

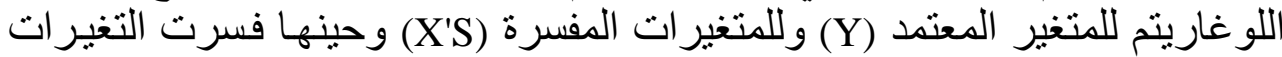

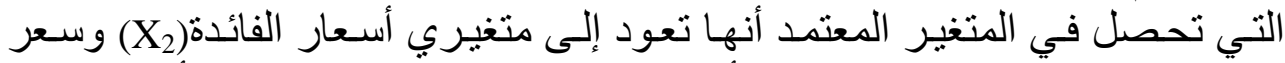

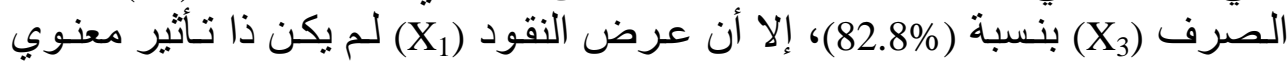
لعدم تجاوز الاختبار ات الإحصائية.

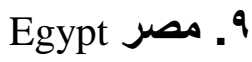

تمت معالجة بيانات مصر منلما حصل مع تثيلي وحينها كانت القوة التفسيرية

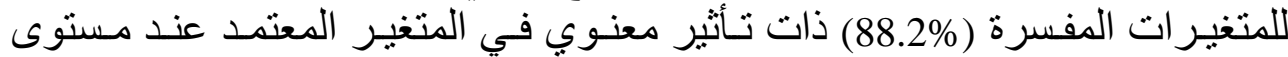

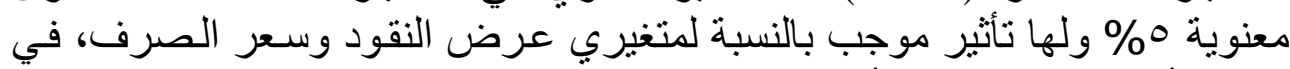
حين التأثير السالب لمتغير أسعار الفائدة ونتيجة لارتفاع القوة التفسيرية تم إخضاع التهاع 
الأنموذج لاختبار كلاين للتعرف على وجود مشكلة التداخل الخطي بين المتغيرات المفسرة وقد تجاوز المشكلة.

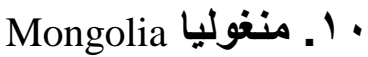

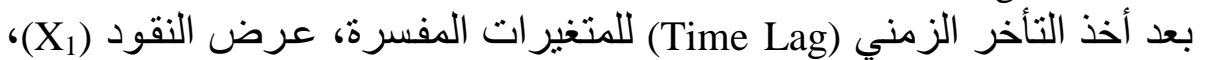

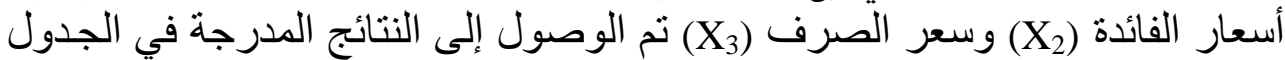

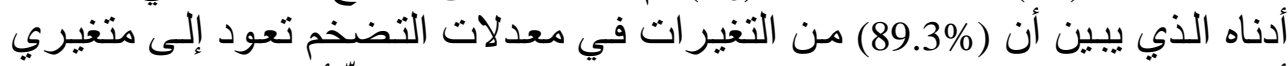

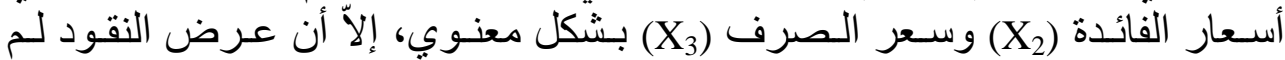

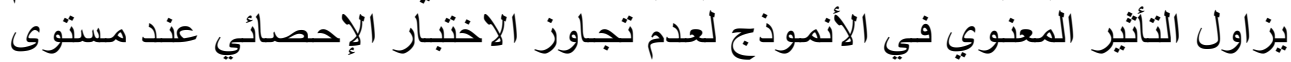

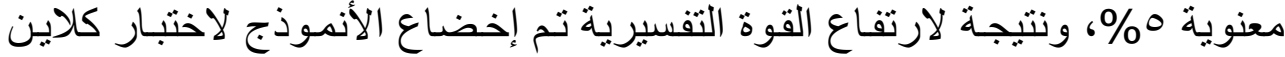

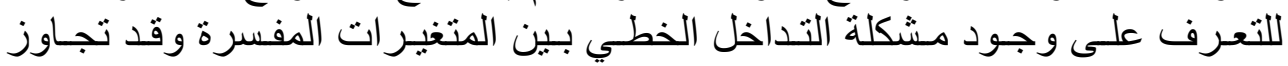
المشكلة

India المئات تم تعديل بيانات الهند على غرار التعديلات التي أجريناهـا في كل من تشيلي

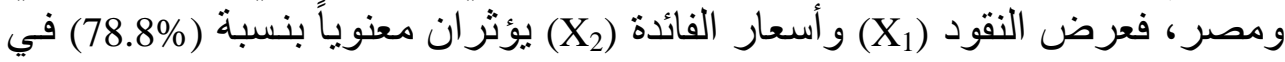

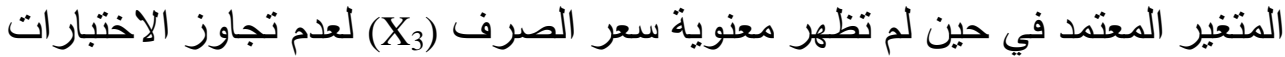

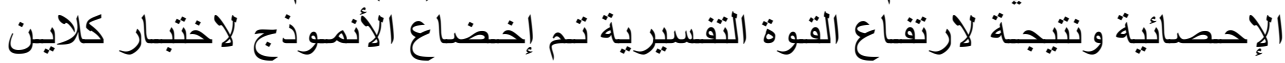

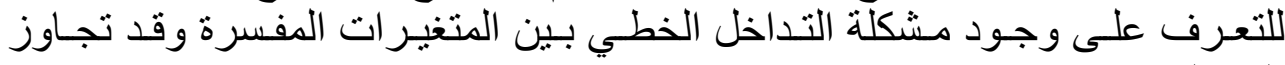
المشكلة.

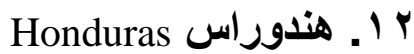

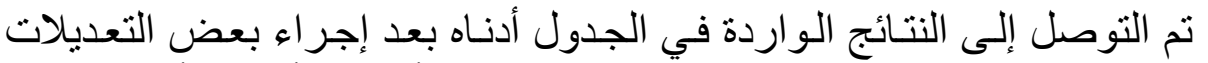

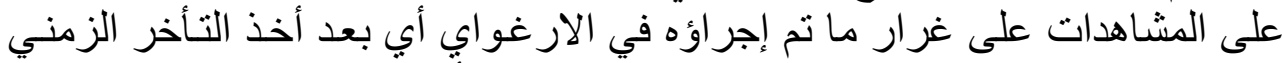

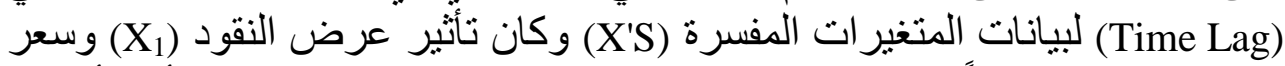

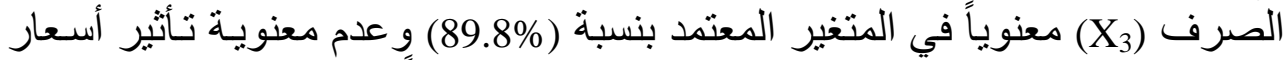

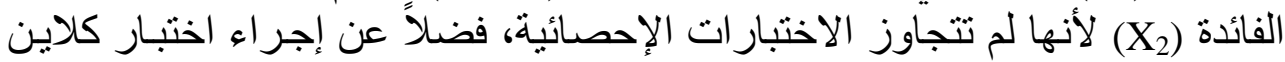

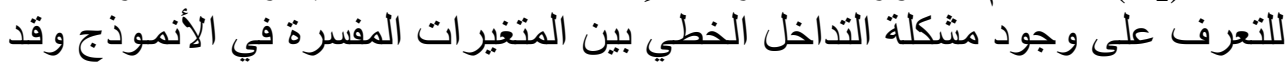

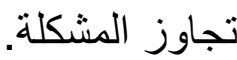

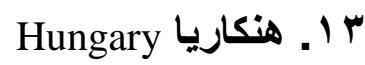

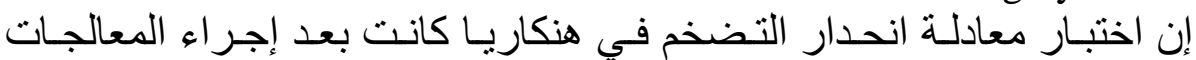

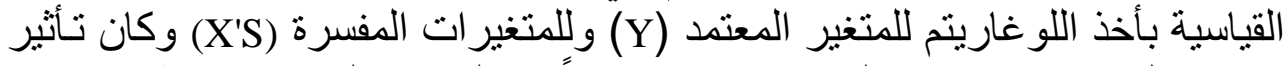

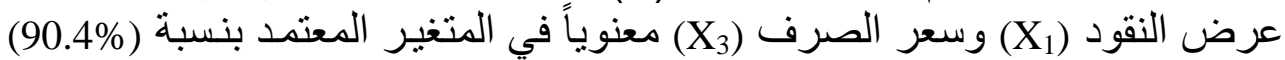

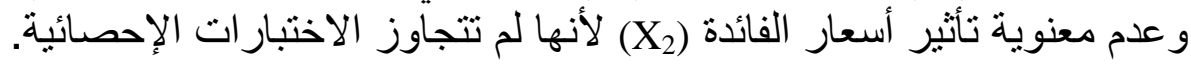


الدكتور الدليمي والسبعاوي [ج • r]

نتائج اختبار بلدان العينة

\begin{tabular}{|c|c|c|c|c|c|c|c|}
\hline \multirow[b]{2}{*}{ العينة } & \multicolumn{4}{|c|}{ معلمات الأنموذج } & \multicolumn{3}{|c|}{ الاختبارات الإحصائية } \\
\hline & $\begin{array}{c}\mathrm{B}_{\mathrm{o}} \\
\mathrm{t} \\
\mathrm{S} . \mathrm{E}\end{array}$ & $\begin{array}{c}\mathrm{B}_{1} \\
\mathrm{t} \\
\text { S.E }\end{array}$ & $\begin{array}{c}\mathrm{B}_{2} \\
\mathrm{t} \\
\text { S.E }\end{array}$ & $\begin{array}{c}\mathrm{B}_{3} \\
\mathrm{t} \\
\text { S.E }\end{array}$ & $\mathrm{R}^{2}$ & $\mathrm{~F}$ & D.W \\
\hline الأرجنتين & $\begin{array}{l}(182) \\
(6.35) \\
28.67\end{array}$ & $\begin{array}{c}29.2 \\
10.40 \\
2.805\end{array}$ & $\begin{array}{l}(2.04) \\
(3.39) \\
0.706\end{array}$ & $\begin{array}{l}(14.5) \\
(6.64 \\
2.177\end{array}$ & $89.5 \%$ & 708.11 & 1.83 \\
\hline الارغواي & $\begin{array}{c}0.142 \\
4.35 \\
0.032\end{array}$ & $\begin{array}{l}0.832 \\
10.18 \\
0.082\end{array}$ & $\begin{array}{l}0.235 \\
2.35 \\
0.10\end{array}$ & $\begin{array}{c}(0.122) \\
(2.06) \\
0.059\end{array}$ & $87.3 \%$ & 43.41 & 2.04 \\
\hline البرازيل & $\begin{array}{c}113 \\
11.13 \\
10.14 \\
\end{array}$ & $\begin{array}{c}0.0525 \\
4.29 \\
0.0123\end{array}$ & $\begin{array}{l}(7.02) \\
(6.25) \\
1.123\end{array}$ & $\begin{array}{l}25.10 \\
10.49 \\
2.389\end{array}$ & $88.9 \%$ & 607.35 & 1.68 \\
\hline بوليفيا & $\begin{array}{c}28.8 \\
4.7 \\
6.12\end{array}$ & $\begin{array}{c}2.68 \\
12.8 \\
0.209\end{array}$ & $\begin{array}{c}(0.365) \\
(3.16) \\
0.116\end{array}$ & $\begin{array}{c}1.36 \\
4.74 \\
0.286\end{array}$ & $77.5 \%$ & 251.02 & 1.17 \\
\hline تركيا & $\begin{array}{c}(3.91) \\
(6.62) \\
0.5905\end{array}$ & $\begin{array}{c}0.21 \\
3.81 \\
0.0005\end{array}$ & $\begin{array}{c}0.101 \\
9.93 \\
0.0101\end{array}$ & $\begin{array}{c}(0.00001) \\
(2.85) \\
0.000005\end{array}$ & $82.8 \%$ & 85.98 & 2.02 \\
\hline تشيلي & $\begin{array}{l}(44.7) \\
(1.77) \\
25.24\end{array}$ & $\begin{array}{c}40.9 \\
10.23 \\
4.001\end{array}$ & $\begin{array}{l}(13.5) \\
(3.46) \\
3.889\end{array}$ & $\begin{array}{c}(23.3) \\
(4.18) \\
5.58\end{array}$ & $77.8 \%$ & 276.07 & 1.71 \\
\hline جامايكا & $\begin{array}{l}(112) \\
(1.4) \\
79.45\end{array}$ & $\begin{array}{c}38.9 \\
3.38 \\
11.49\end{array}$ & $\begin{array}{l}(64.2) \\
(7.94) \\
8.088 \\
\end{array}$ & $\begin{array}{c}5.9 \\
0.38 \\
15.46 \\
\end{array}$ & $80.40 \%$ & 254.39 & 1.8 \\
\hline كولومبيا & $\begin{array}{c}0.055 \\
0.13 \\
0.413\end{array}$ & $\begin{array}{c}0.0029 \\
1.04 \\
0.0028\end{array}$ & $\begin{array}{c}0.0832 \\
6.44 \\
0.0129\end{array}$ & $\begin{array}{c}0.00168 \\
7.38 \\
0.00023\end{array}$ & $82.80 \%$ & 82.06 & 1.01 \\
\hline مصر & $\begin{array}{c}29 \\
0.51 \\
56.93 \\
\end{array}$ & $\begin{array}{c}31.089 \\
8.23 \\
3.778\end{array}$ & $\begin{array}{c}(124.78) \\
(10.5) \\
11.89\end{array}$ & $\begin{array}{c}20.125 \\
6.66 \\
3.02\end{array}$ & $88.20 \%$ & 303.00 & 1.29 \\
\hline منغوليا & $\begin{array}{c}38.3 \\
3.29 \\
11.62 \\
\end{array}$ & $\begin{array}{c}0.0214 \\
1.77 \\
0.012\end{array}$ & $\begin{array}{c}(0.12) \\
(3.04) \\
0.0393\end{array}$ & $\begin{array}{c}0.194 \\
8.87 \\
0.021\end{array}$ & $89.3 \%$ & 928.78 & 1.54 \\
\hline الهند & $\begin{array}{c}164 \\
2.72 \\
60.42\end{array}$ & $\begin{array}{c}21.2 \\
2.28 \\
9.284\end{array}$ & $\begin{array}{c}(105) \\
(7.37) \\
14.2\end{array}$ & $\begin{array}{c}16.3 \\
1.21 \\
13.46\end{array}$ & $78.8 \%$ & 506.42 & 1.49 \\
\hline الـندور اس & $\begin{array}{c}6.82 \\
2.7 \\
2.526 \\
\end{array}$ & $\begin{array}{c}0.0135 \\
19.44 \\
0.0007 \\
\end{array}$ & $\begin{array}{c}(0.349) \\
(1.2) \\
0.2915 \\
\end{array}$ & $\begin{array}{c}5.24 \\
9.29 \\
0.5638 \\
\end{array}$ & $89.80 \%$ & 3612.9 & 1.90 \\
\hline هنكاريا & $\begin{array}{c}2.8 \\
22.79 \\
0.1228\end{array}$ & $\begin{array}{c}0.655 \\
13.04 \\
0.05\end{array}$ & $\begin{array}{c}0.028 \\
1.58 \\
0.0177\end{array}$ & $\begin{array}{c}0.016 \\
3.78 \\
0.0042\end{array}$ & $90.40 \%$ & 59.98 & 1.50 \\
\hline
\end{tabular}

المصدر: من إعداد الباحث بالاعنماد على نتائج الحاسبة الالكترونية . القيم المحصورة بين قوسين ( ) تعني قيماً سالبة. df=20 درجات الحرية 


\section{توصلت الدر اسة إلى مجمو عة من النتائج، هي:}

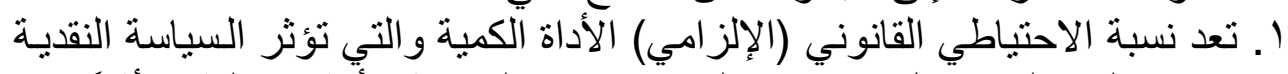

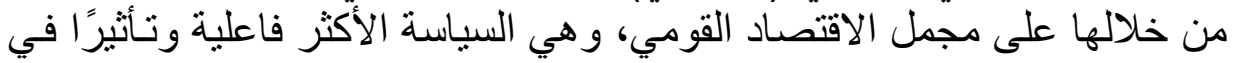

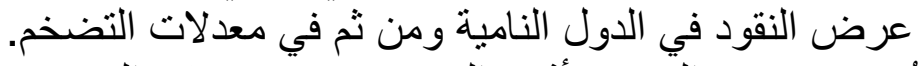

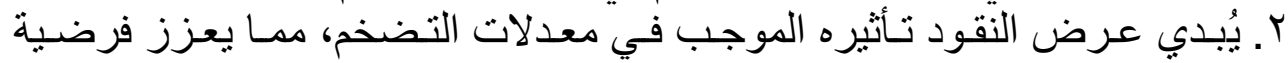

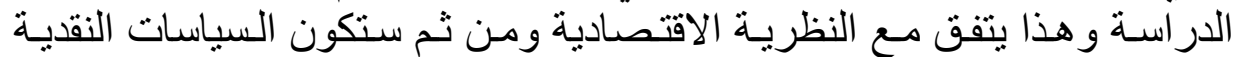
المتشددة من خلال استخدام أدواتها الفاعلة أكثر فاعلية في التأثنير في في معدلات التضخم.

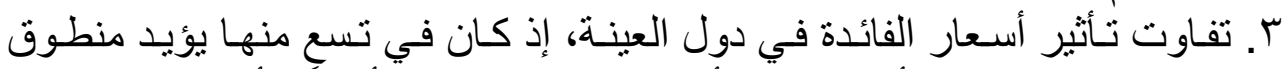

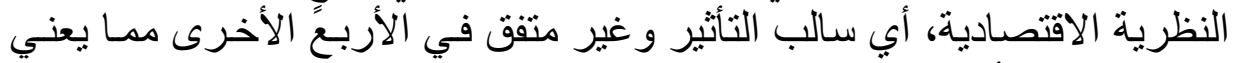

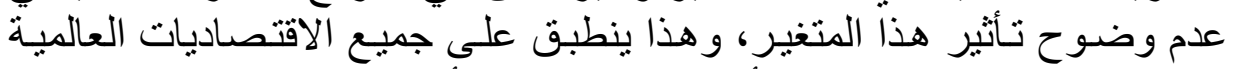
منها ما تكون حساسة لتغير ات أسعار الفائدة ومنها ونا أقل حساسية.

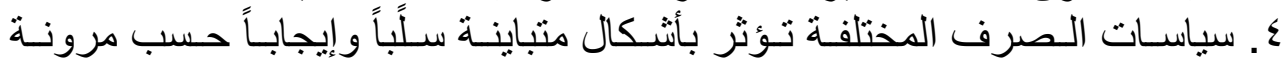

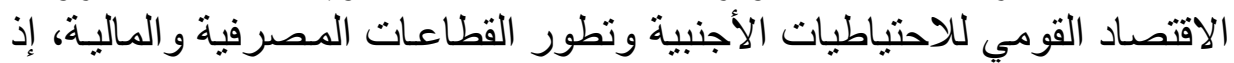

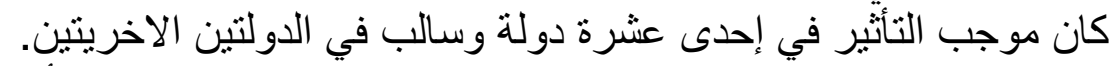

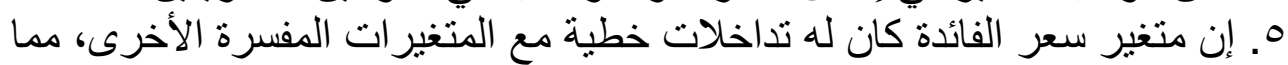

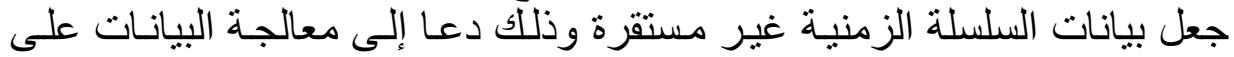

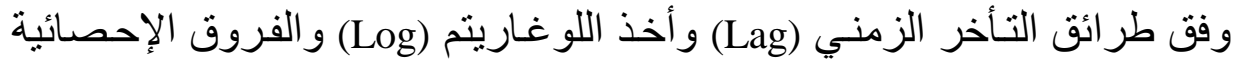
.(Differences) 7. قلة فاعلية سعر الفائدة في البلدان النامية بسبب ضعف الجهاز المصرفي في تلك البلدان.

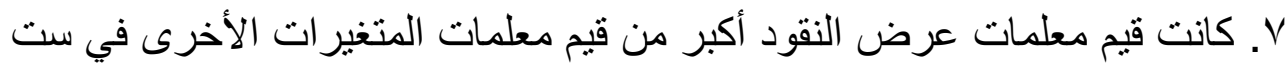

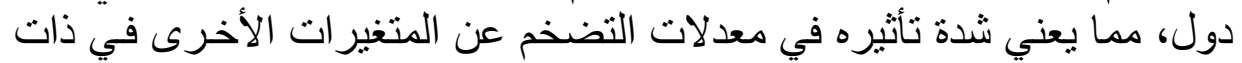

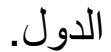
^. يدلل ارتفاع قيمة معامل التحديد (R') على أن متغير ات الأنموذج المفسرة (X'S)

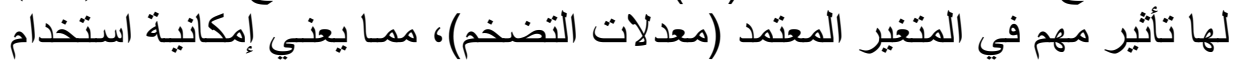

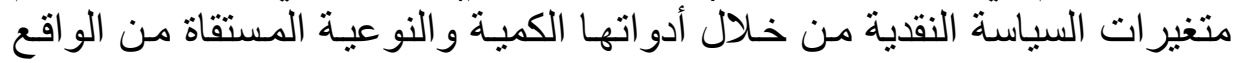
الاقتصادي.

التوصيات ا ـ نتيجة للعلاقة الوطبيدة بين عرض النقود ومعدلات التضخم فعلى السلطة النقديـة

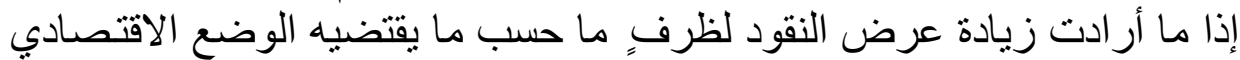

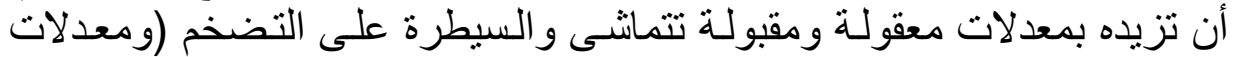




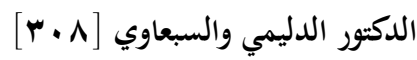

r. بما أن الأدوات الكمية (عمليات السوق المفتوحة ــ معدل الخصم) قليلة الفاعلية

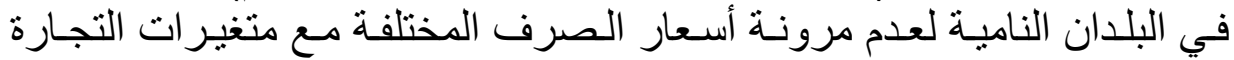

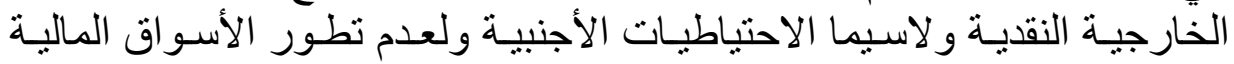

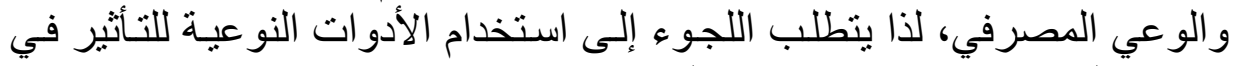
عرض النقود ومن ثم في معدلات التضات التخم. r. يجب عدم إغفال فعالية السياسات المالية المتشددة وفي مقدمتها تقليص الإنيات الإنفاق

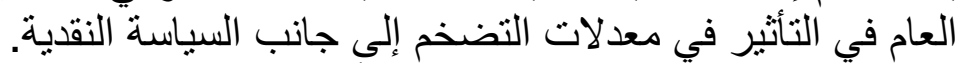

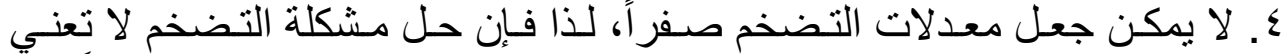

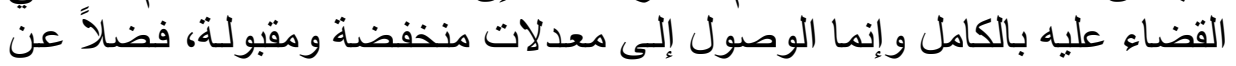

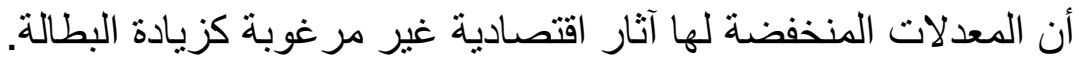

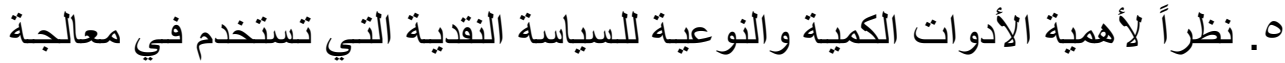

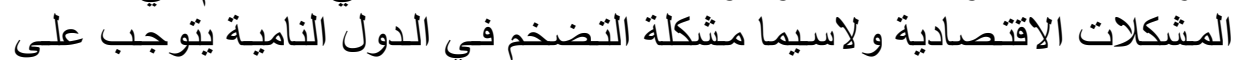

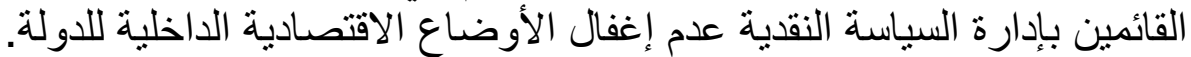

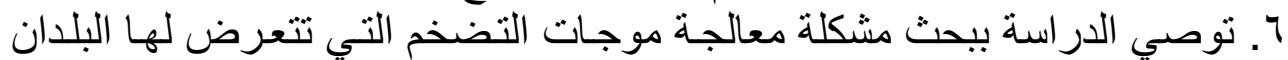

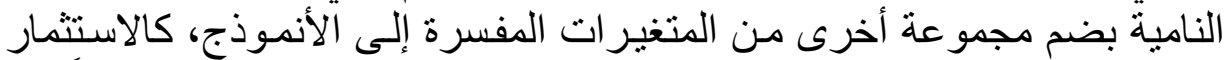

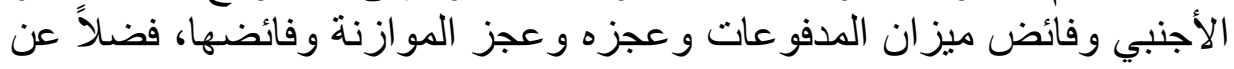
إجر اء الدر اسات المقارنة مع البلدان المتقدمة.

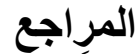

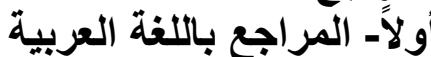

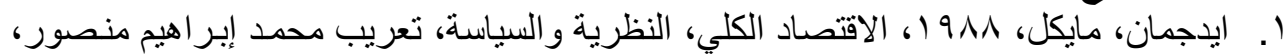

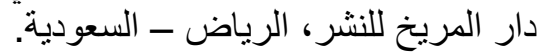

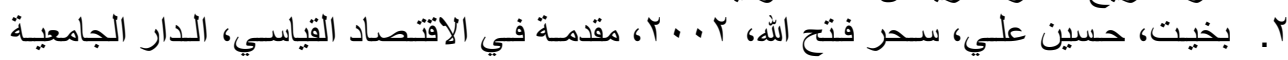

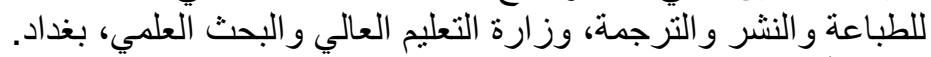

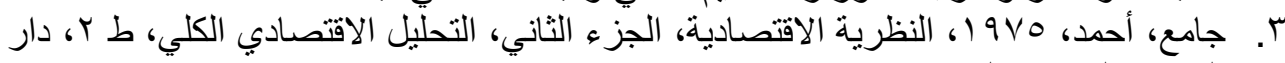

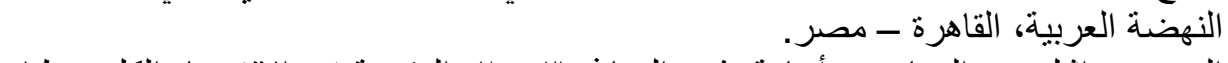

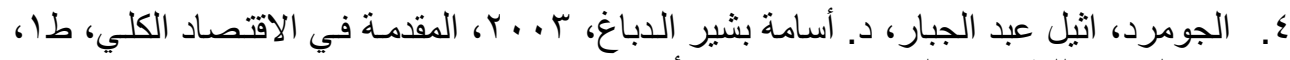

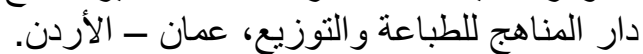

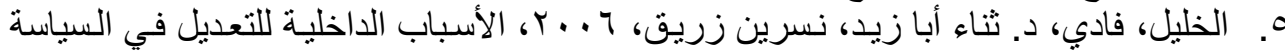
النقاية في سورية، مجلة تنثرين للار اسات و البحوث العلمية ـ سلسلة العلوم والقانونية، المجلد

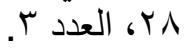
T. الدليمي، عوض فاضل إسماعيل، ـ99 19 ، النقود و البنوك، مطبعة دار الحكمة للطباعة و النشر ،

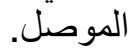

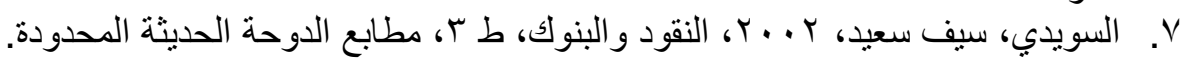

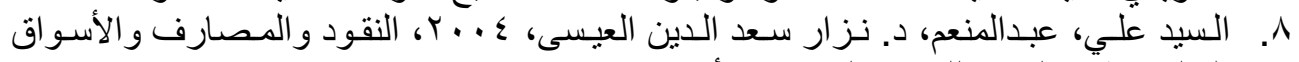
المالية، طأ، الحامد للنشر والتوزيع، الأردن.

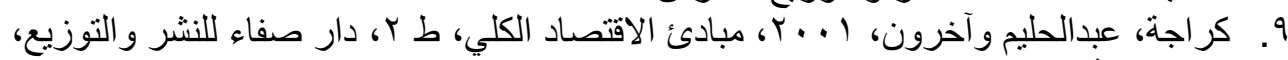

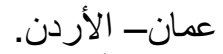

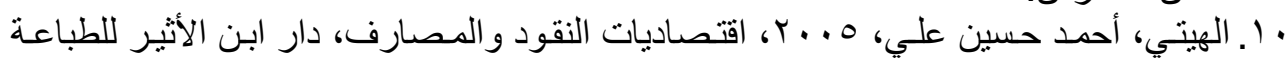

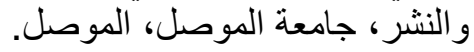




\section{ثانياً المراجع باللغة الأجنبية}

1.Bach, G.L, 1950, Federal Reserve Policy Making, Alfred A. Knopf, New York.

2. David, Andolfatto, 2005, Macroeconomic Theory and Policy, Simon Fraser University dandolfa @ sfu.ca.

3. Einzing, P., 1979, Text Book On Money Policy, London, Macmillaa Stmartis Pres.

4. Federal Reserve Bank Of San Francisco, 2004, U.S. Monetary Policy.

5. Kent, R.P., 1949, Money and Banking, Rinehart and Co., N.Y.

6. Marc Labonte, Gail E. Makinen, 2006, Monetary Policy, Current Policy Conditions, 27 January, Report For Congress

7. Olivier Blanchard, 1997, Macroeconomics, Prentice Hall, New Jersey.

8. Pen, J., 1967, Modern Economics, Translated From The Dutch By T.S. Preston, Penguin Book, Harmonds-Worth, Middlesex, England.

9. Romar, David, 2001, Advanced Macroeconomics, Second Edition, Boston Burr, New York.

10. Ross, M.H., 1964, Income: Analysis Policy, McGraw Hill Books Co . N.Y. 